\title{
Asparagine-EDTA MNPs: A Highly Efficient And Recyclable Magnetic Multifunctional Core-Shell Nanocatalyst For Green Synthesis of Biologically- Active 3,4-Dihydropyrimidin-2(1H)-One Compounds
}

\author{
Negin Rostami \\ Iran University of Science and Technology \\ Mohammad G Dekamin ( $\sim$ mdekamin@iust.ac.ir) \\ Iran University of Science and Technology \\ Ehsan Valiey \\ Iran University of Science and Technology \\ Hamidreza FaniMoghadam \\ Iran University of Science and Technology
}

\section{Research Article}

Keywords: Core-Shell magnetic nanoparticles, Nano-Ordered catalysts, Multi-Component reactions (MCRs), Heterocycles, Green and sustainable chemistry

Posted Date: November 1st, 2021

DOI: https://doi.org/10.21203/rs.3.rs-971598/v1

License: (c) (1) This work is licensed under a Creative Commons Attribution 4.0 International License.

Read Full License 


\section{Abstract}

In this study, the new asparagine grafted on the EDTA-modified $\mathrm{Fe}_{3} \mathrm{O}_{4} @ \mathrm{SiO}_{2}$ core-shell $\left(\mathrm{Fe}_{3} \mathrm{O}_{4} @ \mathrm{SiO}_{2}-\right.$ APTS-EDTA-asparagine) magnetic nanoparticles were prepared and their structures were properly confirmed using different spectroscopic, microscopic and magnetic methods or techniques such as FT-IR, EDX, XRD, FESEM, TEM, TGA and VSM. The $\mathrm{Fe}_{3} \mathrm{O}_{4} @ \mathrm{SiO}_{2}$-APTS-EDTA-asparagine core-shell nanomaterial was examined, as a highly efficient multifunctional and recoverable nanocatalyst, for the synthesis of a wide range of nitrogen-containing heterocycles and biologically-active 3,4-dihydropyrimidin-2(1 H)-one derivatives under solvent-free conditions. It was proved that $\mathrm{Fe}_{3} \mathrm{O}_{4} @ \mathrm{SiO}_{2}$-APTS-EDTA-asparagine MNPs, as a catalyst having excellent thermally and magnetic stability, specific morphology and acidic sites, can activate the Biginelli reaction components. Moreover, environmental-friendliness and nontoxic nature properties of the catalyst, cost effectiveness, low catalyst loading, easy separation of the catalyst from products and short time of reaction are some of the remarkable advantages of this green protocol.

\section{Introduction}

Green chemistry has played a key role in the development of human civilization ${ }^{1-4}$. In this regard, magnetic nanoparticles (MNPs) have received considerable interest because of their unique properties ${ }^{5}$. The outstanding properties of MNPs have made them superior and indispensable in many areas of industry and academia including information storage ${ }^{6}$, medicine ${ }^{7}$, drug delivery ${ }^{8}$, magnetic resonance imaging (MRI) ${ }^{9,10}$, biomedical applications ${ }^{5,11,12}$, and environmental remediation ${ }^{13}$ as well as heterogeneous catalysis ${ }^{14-17}$. In academia, MNPs represent a promising new technology for performing chemical reactions because they are separated from the reaction medium, comfortably ${ }^{18,19}$. In industry, due to the importance of the cost of chemical processes and the reuse of catalysts, special attention is paid to these nanoparticles ${ }^{20,21}$. MNPs tend to agglomerate under a magnetic field that reduces their surface to volume ratio and consequently decreases catalytic activity ${ }^{22}$. Therefore, MNPs must be stabilized to improve their properties and prevent undesirable agglomeration ${ }^{23}$. In fact, they are coated with a protective layer such as carbon layers ${ }^{24,25}$, organic polymer ${ }^{26}$ or silica ${ }^{27,28}$.

Moreover, multi-component reactions (MCRs) are the most desirable powerful synthetic route in which three or more reactants come together in a single reaction vessel to form a wide range of acyclic or heterocyclic compounds by the one-pot processes ${ }^{29,30}$. MCRs afford extended molecular complexity and diversity from simple starting materials with high atom economy, which have found application in medicinal and natural products chemistry ${ }^{31,32}$. Indeed, the most significant feature of MCRs is generating almost no by-products or simple molecules such as $\mathrm{H}_{2} \mathrm{O}$ or $\mathrm{EtOH}^{33-37}$. Hence, in agreement of the green and sustainable chemistry process, development and the advancement of catalysts to promote MCRs are very important in synthetic and medicinal chemistry ${ }^{38-40}$.

Among the various types of nitrogen-containing heterocycles, derivatives of 3,4-dihydropyrimidin-2(1 H)one, as biologically-active compounds, have found versatile applications such as anti-bacterial, anti- 
inflammatory, antihypertensive agents, calcium channel blockers, antitumor compounds ${ }^{41-47}$. A simple and general protocol for access to 3,4-dihydropyrimidin-2(1H)-ones involves a three-component one-pot Biginelli cyclocondensation of ethyl acetoacetate, urea and various aldehydes accelerated by different types of catalytic systems such as polymer-supported catalysts ${ }^{48}$, ionic liquids ${ }^{49,50}$, ionic liquid/silica sulfuric acid ${ }^{51}$, metal-organic framework (MOF) ${ }^{52,53}$, montmorillonite clay ${ }^{54}$, magnetic nanoparticles ${ }^{55}$, Lewis acidic zirconium (IV)-salophen perfluorooctanesulfonate or sulfated polyborate ${ }^{56,57}$, nanocrystalline CdS thin film ${ }^{46}$, graphene oxide ${ }^{58,59}$ and mesoporous materials ${ }^{60,61}$ as well as environmental friendly energy inputs such as ultrasound ${ }^{62}$ or microwave irradiation ${ }^{63}$. Most of the reported methods in this regard have the role of heterogeneous catalysts and high value. However, these have problems such as complicated and tedious separation of products and catalysts, toxic reaction conditions, long reaction times and low yields. Therefore, there is still room to develop more environmentally-benign protocols to promote the Biginelli MCR condensation.

In many previous reports, ethylenediaminetetraacetic acid (EDTA) has been used as an ion exchange and chelating agent for various metal ions ${ }^{64-66}$, but this compound has a good ability as an inexpensive and non-toxic cross-linker to make strong bonds with organic materials having nucleophilic centers ${ }^{67}$. On the other hand, asparagine is one of the 20 amino acids found in the cells of the human body and is essential for maintaining balance in the central nervous system ${ }^{68}$. Asparagine can act as a biocompatible precursor and bifunctional organocatalyst due to its high natural abundance and costeffectiveness with acidic and basic sites ${ }^{69,70}$.

In this research, we herein report the synthesis and characterizations of new asparagine grafted on the EDTA-modified $\mathrm{Fe}_{3} \mathrm{O}_{4} @ \mathrm{SiO}_{2}$ core-shell magnetic nanoparticles $\left(\mathrm{Fe}_{3} \mathrm{O}_{4} @ \mathrm{SiO}_{2}\right.$-APTS-EDTA-asparagine), as a magnetically recoverable nanocatalyst, to promote the Biginelli reaction efficiently at $60^{\circ} \mathrm{C}$ under solvent-free conditions (Fig. 1).

\section{Results And Discussion}

\section{Characterization of the $\mathrm{Fe}_{3} \mathrm{O}_{4} @ \mathrm{SiO}_{2}$-APTS-EDTA-asparagine nanocatalyst (1)}

The overall procedure for the synthesis of $\mathrm{Fe}_{3} \mathrm{O}_{4} @ \mathrm{SiO}_{2}$-APTS-EDTA-asparagine (1) has been summarized in Fig. 1. At first, the obtained magnetic nanoparticles were characterized using different physicochemical techniques such as Fourier transform infrared (FT-IR) spectroscopy, energy-dispersive X-ray (EDX) spectroscopy, field emission scanning electron microscopy (FESEM), transmission electron microscopy (TEM), X-ray diffraction spectroscopy (XRD), vibrating sample magnetometer (VSM), and thermogravimetric analysis (TGA).

The FT-IR spectroscopy was employed to determine the functional groups and structure of $\mathrm{Fe}_{3} \mathrm{O}_{4}(\mathrm{a})$, $\mathrm{Fe}_{3} \mathrm{O}_{4} @ \mathrm{SiO}_{2}$ (b), $\mathrm{Fe}_{3} \mathrm{O}_{4} @ \mathrm{SiO}_{2}$-APTS (c), $\mathrm{Fe}_{3} \mathrm{O}_{4} @ \mathrm{SiO}_{2}$-APTS-EDTA (d) and $\mathrm{Fe}_{3} \mathrm{O}_{4} @ S \mathrm{SiO}_{2}-\mathrm{APTS}$-EDTA- 
asparagine (e). The results are presented in Fig. 2. In the spectra of $\mathrm{Fe}_{3} \mathrm{O}_{4}$ nanoparticles (Fig. 2a) the bands displayed at $620 \mathrm{~cm}^{-1}$ and about $3410 \mathrm{~cm}^{-1}$ are attributed to stretching vibration of $\mathrm{Fe}-\mathrm{O}$ bond and surface hydroxyl groups, respectively. These peaks were observed in all five samples isolated at the different synthetic stages. In the FT-IR spectrum of $\mathrm{Fe}_{3} \mathrm{O}_{4} @ \mathrm{SiO}_{2}$ (Fig. 2b), the absorption bands at 881 and $1036 \mathrm{~cm}^{-1}$ can be ascribed to the presence of Si-O-Si symmetric and $\mathrm{Si}-\mathrm{O}-\mathrm{Si}$ asymmetric stretching modes, reflecting the coating of silica layer on the magnetite nanoparticles ${ }^{71} . \mathrm{SP}^{3} \mathrm{C}-\mathrm{H}$ stretching vibrations about $2922 \mathrm{~cm}^{-1}$ confirmed the presence of the anchored (3-aminopropyl) triethoxysilane (APTS) group and the band about $1400 \mathrm{~cm}^{-1}$ is assigned to the bending of $-\mathrm{NH}$ groups of $\mathrm{Fe}_{3} \mathrm{O}_{4} @ \mathrm{SiO}_{2}$-APTS MNPs (Fig. 2c) ${ }^{72}$. In the FT-IR spectrum of $\mathrm{Fe}_{3} \mathrm{O}_{4} @ \mathrm{SiO}_{2}$-APTS-EDTA (Fig. 2d), the peaks at $1635 \mathrm{~cm}^{-1}, 1707 \mathrm{~cm}^{-1}$ and $1760 \mathrm{~cm}^{-1}$ corresponding to the $\mathrm{C}=0$ vibration of amide, acid and anhydride groups, respectively. In the last step, the peak at $1760 \mathrm{~cm}^{-1}$, which belongs to the anhydride group has been removed and new peaks at $1651 \mathrm{~cm}^{-1}$ and $1737 \mathrm{~cm}^{-1}$ are attributed to the amide and acid groups in the surface of $\mathrm{Fe}_{3} \mathrm{O}_{4} @ \mathrm{SiO}_{2}$-APTS-EDTA-asparagine (Fig. 2e). These results from the FT-IR spectrum confirm that the silica coating and subsequent steps have been successfully performed on the surface of $\mathrm{Fe}_{3} \mathrm{O}_{4}$.

Compositional analysis of the $\mathrm{Fe}_{3} \mathrm{O}_{4} @ \mathrm{SiO}_{2}$-APTS-EDTA-asparagine magnetic nanocatalyst (1) was carried out using energy-dispersive X-ray spectroscopy (EDX). The EDX spectra of the $\mathrm{Fe}_{3} \mathrm{O}_{4} @ \mathrm{SiO}_{2}$-APTSEDTA-asparagine nanomaterial (1) are depicted in Fig. 3. In addition, the EDX analysis showed the welldefined peaks related to $\mathrm{C}, \mathrm{O}, \mathrm{N}, \mathrm{Si}$ and $\mathrm{Fe}$ in the structure of $\mathrm{Fe}_{3} \mathrm{O}_{4} @ \mathrm{SiO}_{2}$-APTS-EDTA-asparagine (1) with the percentages of $40.32,36.57,11.69,6.34$ and 5.08 , respectively.

The morphology and texture of $\mathrm{Fe}_{3} \mathrm{O}_{4} @ \mathrm{SiO}_{2}$-APTS-EDTA-asparagine MNPs (1) were indicated by FESEM analysis and their photographs were presented in Fig. 4. According to these FESEM photographs, the size and surface shape of nanoparticles are well observed, which proves that the particles are spherical and without agglomeration. The FESEM photographs supported the formation of spherically shaped MNPs, which is in accordance with TEM analysis.

The TEM analysis of the $\mathrm{Fe}_{3} \mathrm{O}_{4} @ \mathrm{SiO}_{2}$-APTS-EDTA-asparagine (1) MNPs in two scales is shown in Fig. 5. The TEM images demonstrated structural order and the morphology suggested that the magnetite nanoparticles have an average diameter size of $41 \mathrm{~nm}$.

The XRD pattern of $\mathrm{Fe}_{3} \mathrm{O}_{4} @ \mathrm{SiO}_{2}$-APTS-EDTA-asparagine (1) was shown in Fig. 6. The reflection peaks were compared with the reference standard patterns related to EDTA (card no. JCPDS, 00-033-1672), $\mathrm{Fe}_{3} \mathrm{O}_{4}$ (card no. JCPDS, 01-088-0315) and asparagine (card no. JCPDS, 00-031-1542). The sharp peaks in this pattern are generated by combining several peaks. These new sharp peaks are ascribed to the produced $\mathrm{Fe}_{3} \mathrm{O}_{4} @ \mathrm{SiO}_{2}$-APTS-EDTA-asparagine MNPs structures after modification reactions by EDTA and asparagine, respectively. 
The magnetic properties of MNPs were measured via vibrating sample magnetometery (VSM). The magnetic attributes of $\mathrm{Fe}_{3} \mathrm{O}_{4}$ and $\mathrm{Fe}_{3} \mathrm{O}_{4} @ \mathrm{SiO}_{2}$-APTS-EDTA-asparagine MNPs (1) were measured out at room temperature by applied magnetic field -1000 to +1000 Oersted. According to data presented in Fig. 7, The values of the magnetization saturation (Ms) for $\mathrm{Fe}_{3} \mathrm{O}_{4}$ and $\mathrm{Fe}_{3} \mathrm{O}_{4} @ \mathrm{SiO}_{2}$-APTS-EDTA-asparagine MNPs (1) are 73.12 and $20.84 \mathrm{emu} / \mathrm{g}$, respectively. Moreover, the VSM curves of both samples exhibit no hysteresis loops and this property demonstrated that no aggregation occurred in the presence of magnetic fields. A decrease in the magnetic saturation of the $\mathrm{Fe}_{3} \mathrm{O}_{4} @ \mathrm{SiO}_{2}-\mathrm{APTS}$-EDTA-asparagine was observed after coating with $\mathrm{SiO}_{2}$ and functionalization with APTS. However, the magnetic saturation of $\mathrm{Fe}_{3} \mathrm{O}_{4} @ \mathrm{SiO}_{2}$-APTS-EDTA-asparagine (1) is sufficient to be recovered by exerting an external magnet.

Thermal stability of the $\mathrm{Fe}_{3} \mathrm{O}_{4} @ \mathrm{SiO}_{2}$-APTS-EDTA-asparagine nanomaterial (1) was investigated under the air atmosphere over the temperature range of $50-800^{\circ} \mathrm{C}$ (Fig. 8). The $\mathrm{Fe}_{3} \mathrm{O}_{4} @ \mathrm{SiO}_{2}-\mathrm{APTS}$-EDTAasparagine MNPs (1) display three weight loss steps over the temperature range of TGA and the total weight loss of nanocatalyst 1 is around $60 \%$. According to obtained results, in the first step $15 \%$ weight loss in the range of $150-200^{\circ} \mathrm{C}$ is due to the evaporation of adsorbed water and organic solvents that remain in the nanocatalyst through its preparation processes. In addition, $22 \%$ weight loss in the range of $200-400^{\circ} \mathrm{C}$ corresponds to the loss of EDTA-asparagine moiety. In the last step, the sharp weight loss of $23 \%$ at $400-700^{\circ} \mathrm{C}$ can be assigned to the decomposition of APTS moiety in the MNPs framework. These results also indicate that APTS, EDTA and asparagine has been successfully grafted onto the surface of $\mathrm{Fe}_{3} \mathrm{O}_{4} @ \mathrm{SiO}_{2}$. Above $700^{\circ} \mathrm{C}$ only $\mathrm{Fe}_{3} \mathrm{O}_{4}$ was present.

\section{Optimization of conditions in the Biginelli reaction using $\mathrm{Fe}_{3} \mathrm{O}_{4} @ \mathrm{SiO}_{2}$-APTS-EDTA asparagine nanocatalyst (1)}

In our preliminary experiments, the catalytic activity of as prepared catalyst 1 was evaluated in the formation of dihydropyrimidin-2 $(1 H)$-one derivatives by the Biginelli condensation. For this purpose, reaction conditions were optimized using the equimolar mixtures of urea $(2,1 \mathrm{mmol})$, 4-

chlorobenzaldehyde (3a, $1 \mathrm{mmol}$ ) and ethyl acetoacetate $(\mathbf{4 a}, 1 \mathrm{mmol})$ as the model reaction (Eq. $\mathbf{1})$. In a systematic screening, the reaction conditions were investigated precisely by considering of several crucial variables such as catalyst loading, reaction time, solvent and reaction temperature, as given in Table 1. Initially, in the absence of any catalyst and solvent, the progress of model reaction was slow and the yield of the 9-(4-chlorophenyl)-3,3,6,6-tetramethyl-3,4,6,7,9,10-hexahydroacridine-1,8(2H,5H)-dione (5a) was trace, even after a long time (Table 1, entry 1). Then, in the presence of very low amount of $\mathrm{Fe}_{3} \mathrm{O}_{4} @ \mathrm{SiO}_{2^{-}}$ APTS-EDTA-asparagine (1) loading, as a nanocatalyst, without any solvent at room temperature, a good yield of the desired product 5 a was obtained (Table 1, entry 2). To achieve an excellent yield, the reaction temperature was increased to $60^{\circ} \mathrm{C}$ (Table 1, entry 3). Afterward, the model reaction was performed with lower catalyst 1 loading under solvent-free conditions as well as polar and non-polar solvents.

Furthermore, the effect of temperature and different solvents was investigated (Table 1, entries 4-13). Also, the model reactions in the presence of EDTA and asparagine were separately investigated, but lower yields of the desired product $\mathbf{5 a}$ were isolated (Table 1, entries 14-15). 
Following the steps of optimizing the reaction conditions, the effect of different solvents and amount of catalyst loadings are summarized in Fig. 9. The model reaction was investigated under solvent-free conditions and different solvents such as $\mathrm{EtOH}, \mathrm{MeOH}, \mathrm{EtOH} / \mathrm{H}_{2} \mathrm{O}(1: 1)$, and DMF using $\mathrm{Fe}_{3} \mathrm{O}_{4} @ \mathrm{SiO}_{2}-$ APTS-EDTA-asparagine nanocatalyst (1) with different loading of the catalyst 1 . According to the obtained findings summarized in Table 1 and Fig. 9, the optimum reaction conditions were found to be 10 mg of $\mathrm{Fe}_{3} \mathrm{O}_{4} @ \mathrm{SiO}_{2}$-APTS-EDTA-asparagine nanocatalyst (1) loading under solvent-free conditions at 60 ${ }^{\circ} \mathrm{C}$.

After the above experiments, the scope of reaction was expanded by using aromatic aldehydes having electron-withdrawing or electron-donating groups under the optimized conditions (Eq. 2). The results are summarized in Table 2. As expected, in this novel magnetic heterogeneous catalytic system the reaction rate of aldehydes with electron-donating groups was slower than electron-releasing ones and required more time to complete the reaction. An alternative variation in this reaction was accomplished by utilizing methyl acetoacetate (4b) instead of ethyl acetoacetate (4a) for the synthesis of different Biginelli products. It is worth noting that all the reactions represented very good to excellent yields under solventfree conditions in short time.

\section{The proposed mechanism for the synthesis of 3,4- dihydropyrimidin-2(1H)-one derivatives in the presence of $\mathrm{Fe}_{3} \mathrm{O}_{4} @ \mathrm{SiO}_{2}$-APTS-EDTA-asparagine nanocatalyst (1)}

The proposed mechanism based on the three-component strategy for the synthesis of 3,4dihydropyrimidin-2 $(1 \mathrm{H})$-one derivatives catalyzed by $\mathrm{Fe}_{3} \mathrm{O}_{4} @ \mathrm{SiO}_{2}$-APTS-EDTA-asparagine nanocatalyst (1) is presented in Fig. 10. At first, the carbonyl group of aldehyde is activated by $\mathrm{Fe}_{3} \mathrm{O}_{4} @ \mathrm{SiO}_{2}$-APTSEDTA-asparagine (1) to form intermediate (I) through the condensation with urea (2). Afterward, iminium intermediate (III) is produced after leaving the $\mathrm{H}_{2} \mathrm{O}$ in the presence of the magnetic nanocatalyst. Meanwhile, intermediate (III) reacts with the enol form of the alkyl acetoacetate (4) and the corresponding intermediate (IV) is generated. Eventually, intramolecular cyclization occurs which is followed by dehydration of intermediate $(\mathbf{V})$. At the end of the catalytic cycle, 3,4-dihydropyrimidin-2(1 H)-ones are produced and the catalyst is recycled ${ }^{60}$.

\section{Green chemistry metrics}

In this part of our research, green chemistry metrics for the synthesis of 3,4-dihydropyrimidin-2(1H)-one by $\mathrm{Fe}_{3} \mathrm{O}_{4} @ \mathrm{SiO}_{2}$-APTS-EDTA-asparagine nanocatalyst (1) were calculated and the results are summarized in Table $3^{79,80}$. Hence, several parameters of the green approach such as environmental factor (E factor), process mass intensity, reaction mass efficiency, carbon efficiency, and atom economy were evaluated and compared to the ideal values ${ }^{81}$. As presented in Table 3 , all calculated values are close to the ideal values and were reported in supporting information. 


\section{Reusability of the $\mathrm{Fe}_{3} \mathrm{O}_{4} @ \mathrm{SiO}_{2}$-APTS-EDTA-asparagine nanocatalyst (1)}

One of the critical scales in catalytic processes is reusability and recyclability of the catalyst. For evaluation of this parameter, the model reaction was examined using $\mathrm{Fe}_{3} \mathrm{O}_{4} @ \mathrm{SiO}_{2}$-APTS-EDTAasparagine (1) for four runs. At the end of the reaction, the catalyst 1 was removed using an external magnet and the recycled catalyst was washed with dry toluene, dried and used in a subsequent model reaction. The obtained results are summarized in Fig. 11. Considering the results of isolated yields of products, the catalytic activity of $\mathrm{Fe}_{3} \mathrm{O}_{4} @ \mathrm{SiO}_{2}$-APTS-EDTA-asparagine nanocatalyst (1) after four runs is slightly reduced, which demonstrates proper conservancy of the catalytic activity after recycling.

\section{Comparative study of $\mathrm{Fe}_{3} \mathrm{O}_{4} @ \mathrm{SiO}_{2}$-APTS-EDTA-asparagine nanocatalyst (1) and other catalysts for the Biginelli reaction}

In order to compare the optimal catalytic activity and reaction conditions of the $\mathrm{Fe}_{3} \mathrm{O}_{4} @ \mathrm{SiO}_{2}$-APTS-EDTAasparagine nanocatalyst (1) with previously reported catalysts for the three-component Biginelli reaction, we compared reaction conditions and yield of desired product (5a) in Table 4. As it can be observed from data in Table 4, all catalytic systems are capable of producing the desired product with satisfactory yields but $\mathrm{Fe}_{3} \mathrm{O}_{4} @ \mathrm{SiO}_{2}$-APTS-EDTA-asparagine nanocatalyst (1) in terms of yield and time factors, the reaction temperature, solvent and amount of catalyst loading demonstrates better performance than the other catalysts. Furthermore, additional advantage of this protocol is its easy separation from the crude products by using an external magnet compared to the most of reported heterogeneous catalytic systems.

\section{Experimental}

\section{Chemicals and Instrumentation}

Ferric chloride $\left(\mathrm{FeCl}_{3} \cdot 6 \mathrm{H}_{2} \mathrm{O}\right)$, Ferrous chloride tetrahydrate $\left(\mathrm{FeCl}_{2} \cdot 4 \mathrm{H}_{2} \mathrm{O}\right)$, (3-aminopropyl) triethoxysilane (APTS, 99\%), tetraethyl orthosilicate (TEOS, 99\%), ammonia (25 wt\%), EDTA (MW $=292.24 \mathrm{~g} / \mathrm{mol}$ ), and asparagine ( $M W=132.12 \mathrm{~g} / \mathrm{mol}$ ) were purchased from Merck and used without further purification. Urea, ethyl acetoacetate and aromatic aldehydes were purchased from international chemical companies including Merck and Sigma-Aldrich. The analytical TLC experiments were accomplished using Merck Kieselgel 60 F-254 Al-plates and then visualized by UV light and iodine vapour. Melting points of the products were measured on an Electrothermal 9100 apparatus and uncorrected. The functional groups of the samples were identified by FT-IR spectroscopy on a Perkin Elmer, Frontier FT-MIR spectrometer in the range of $600-4000 \mathrm{~cm}^{-1}$ using $\mathrm{KBr}$ discs. The morphology of the nanocatalyst was observed by FESEM 
TESCAN-MIRA3 and TEM Philips EM 208S. TGA curves of the $\mathrm{Fe}_{3} \mathrm{O}_{4} @ \mathrm{SiO}_{2}$-APTS-EDTA-asparagine (1) were recorded by Bahr company STA 504. X-ray diffraction (XRD) pattern of the catalyst 1 was taken by the Bruker D8 Advance device. The composition of the catalyst was determined by energy-dispersive Xray (EDX) spectroscopy using a Numerix DXP-X10P instrument. Magnetization measurements were carried out on a BHV-55 vibrating sample magnetometer (VSM). ${ }^{1} \mathrm{H}$ NMR spectra of the isolated products were recorded at $500 \mathrm{MHz}$ using a Varian-INOVA spectrometer.

\section{General procedure for preparation of the magnetic $\mathrm{Fe}_{3} \mathrm{O}_{4}$ nanoparticles}

Preparation of $\mathrm{Fe}_{3} \mathrm{O}_{4}$ nanoparticles were according to a reported general method ${ }^{83}$. In this procedure, in a $100 \mathrm{~mL}$ round-bottomed flask $\mathrm{FeCl}_{3} \cdot 6 \mathrm{H}_{2} \mathrm{O}(4.6 \mathrm{~g}, 0.017 \mathrm{~mol})$ and $\mathrm{FeCl}_{2} \cdot 4 \mathrm{H}_{2} \mathrm{O}(2.3 \mathrm{~g}, 0.011 \mathrm{~mol})$ were dissolved in deionized water $(60 \mathrm{~mL})$ and stirred for $30 \mathrm{~min}$. Subsequently, aqueous $\mathrm{NH}_{3}(10 \mathrm{~mL})$ was added dropwise into the mixture and heated to $40^{\circ} \mathrm{C}$ under $\mathrm{N}_{2}$ atmosphere for $2 \mathrm{~h}$. The black solution was poured from the reaction vessel and $\mathrm{Fe}_{3} \mathrm{O}_{4}$ MNPs precipitates were separated from the solution using an external magnet, washed five times with deionized water and $\mathrm{EtOH}$, and dried in the oven at $50^{\circ} \mathrm{C}$ for $24 \mathrm{~h}$.

\section{General procedure for preparation of the silica-coated magnetic nanoparticles $\left(\mathrm{Fe}_{3} \mathrm{O}_{4} @ \mathrm{SiO}_{2}\right)$}

In accordance to the modified Stöber method, silica-coated $\mathrm{Fe}_{3} \mathrm{O}_{4}$ nanoparticles $\left(\mathrm{Fe}_{3} \mathrm{O}_{4} @ \mathrm{SiO}_{2}\right)$ were produced by a solvothermal reaction ${ }^{84}$. For this purpose, the $\mathrm{Fe}_{3} \mathrm{O}_{4} \mathrm{MNPs}(1.0 \mathrm{~g})$ were dispersed in $30 \mathrm{~mL}$ of distilled water and ultrasonicated for $30 \mathrm{~min}$. Then, a mixture of aqueous $\mathrm{NH}_{3}(2 \mathrm{~mL})$ and $\mathrm{EtOH}(40$ $\mathrm{mL}$ ) were added dropwise to the magnetite mixture and ultrasonicated for $30 \mathrm{~min}$. Then, a mixture of TEOS $(2 \mathrm{~mL})$ and EtOH $(40 \mathrm{~mL})$ were added slowly to the suspension solution under continuous stirring for $24 \mathrm{~h}$ at $60^{\circ} \mathrm{C}$. Eventually, the $\mathrm{Fe}_{3} \mathrm{O}_{4} @ \mathrm{SiO}_{2}$ core-shell MNPs were collected using an external magnet, washed with deionized water and $\mathrm{EtOH}$ and dried in the oven at $50^{\circ} \mathrm{C}$ for $5 \mathrm{~h}$.

\section{Modification of the $\mathrm{Fe}_{3} \mathrm{O}_{4} @ \mathrm{SiO}_{2} \mathrm{NPs}$ by (3-aminopropyl) triethoxysilane ( $\mathrm{Fe}_{3} \mathrm{O}_{4} @ \mathrm{SiO}_{2}$-APTS)}

$\mathrm{Fe}_{3} \mathrm{O}_{4} @ \mathrm{SiO}_{2}$ core-shell MNPs were modified with (3-aminopropyl) triethoxysilane (APTS) using a typical modified method ${ }^{85}$. Briefly, the $\mathrm{Fe}_{3} \mathrm{O}_{4} @ \mathrm{SiO}_{2}$ NPs $(1.0 \mathrm{~g})$ were ultrasonicated in $30 \mathrm{~mL}$ dried toluene. Subsequently, APTS $(2.0 \mathrm{~mL})$ was added to the magnetic mixture and stirred at $105^{\circ} \mathrm{C}$ for $24 \mathrm{~h}$. After washing with dry toluene, the obtained MNPs separated and dried at $60^{\circ} \mathrm{C}$ for $12 \mathrm{~h}$ in a vacuum oven to prepare the $\mathrm{Fe}_{3} \mathrm{O}_{4} @ \mathrm{SiO}_{2}$-APTS MNPs.

\section{Preparation of the EDTA functionalized magnetic nanoparticles $\left(\mathrm{Fe}_{3} \mathrm{O}_{4} @ \mathrm{SiO}_{2}\right.$-APTS-EDTA)}


In a round-bottom flask, magnetic $\mathrm{Fe}_{3} \mathrm{O}_{4} @ \mathrm{SiO}_{2}$-APTS NPs $(1.0 \mathrm{~g})$ were added to dry toluene $(25 \mathrm{~mL})$ and dispersed with ultrasonic for $15 \mathrm{~min}$. Then, EDTA dianhydride $(1.0 \mathrm{~g})$ - synthesized according to Repo et $\mathrm{al}^{86}$ - and acetic anhydride added to the mixture and stirred at $80^{\circ} \mathrm{C}$ under $\mathrm{N}_{2}$ atmosphere for $24 \mathrm{~h}$. The magnetic $\mathrm{Fe}_{3} \mathrm{O}_{4} @ \mathrm{SiO}_{2}$-APTS-EDTA NPs were washed five times with EtOH followed by drying at $60^{\circ} \mathrm{C}$ for $6 \mathrm{~h}$ in a vacuum oven.

\section{Preparation of the asparagine grafted on the EDTA-modified $\mathrm{Fe}_{3} \mathrm{O}_{4} @ \mathrm{SiO}_{2}$ core-shell magnetic nanoparticles $\left(\mathrm{Fe}_{3} \mathrm{O}_{4} @ \mathrm{SiO}_{2}\right.$-APTS-EDTA-asparagine, 1)}

In the last step, the magnetic $\mathrm{Fe}_{3} \mathrm{O}_{4} @ \mathrm{SiO}_{2}$-APTS-EDTA NPs were dispersed in $25 \mathrm{~mL}$ of dry toluene and asparagine $(1.0 \mathrm{~g})$ was added to the magnetic mixture and stirred under reflux conditions and $\mathrm{N}_{2}$ atmosphere for $24 \mathrm{~h}$. Magnetic precipitates were separated using an external magnet and after drying in the oven, brown powder of $\mathrm{Fe}_{3} \mathrm{O}_{4} @ \mathrm{SiO}_{2}$-APTS-EDTA-asparagine nanocatalyst (1) was obtained.

\section{General procedure for the synthesis of 3,4-dihydropyrimidin- 2(1H)-one (5a-5t) catalyzed by $\mathrm{Fe}_{3} \mathrm{O}_{4} @ \mathrm{SiO}_{2}$-APTS-EDTA- asparagine nanomaterial (1)}

A mixture of urea $(2,1.0 \mathrm{mmol})$, aromatic aldehyde $(3,1.0 \mathrm{mmol})$, ethyl or methyl acetoacetate $(4,1.0$ mmol), and $\mathrm{Fe}_{3} \mathrm{O}_{4} @ \mathrm{SiO}_{2}$-APTS-EDTA-asparagine $(1,10 \mathrm{mg})$ were added under solvent-free conditions for an appropriate time indicated in Table 2. After completion of the reaction, as monitored by TLC [eluent: $\mathrm{n}$ hexane: EtOAc: 3:1], the catalyst was separated using an external magnet and the residue was concentrated to result in the crude product. Finally, the crude product was recrystallized from EtOH to obtain the pure product.

\section{Conclusion}

In summary, the novel and thermally stable asparagine grafted on EDTA-modified $\mathrm{Fe}_{3} \mathrm{O}_{4} @ \mathrm{SiO}_{2}$ core-shell magnetic nanoparticles $\left(\mathrm{Fe}_{3} \mathrm{O}_{4} @ \mathrm{SiO}_{2}\right.$-APTS-EDTA-asparagine) was prepared for the first time. The $\mathrm{Fe}_{3} \mathrm{O}_{4} @ \mathrm{SiO}_{2}$-APTS-EDTA-asparagine heterogeneouse nanocatalyst was used for highly efficient, facile, and green and sustainable synthesis of 3,4-dihydropyrimidin-2(1 H)-one derivatives in a one-pot and threecomponent protocol through cyclocondensation of alkyl acetoacetate, urea and various aldehydes under solvent-free conditions. Consistency with the ideal values of green chemistry parameters, easy work up procedure, good to excellent yields in shorter reaction times, fast separation and recyclability of the catalyst are the additional advantages for its application in academic and industrial purposes. 


\section{Declarations}

\section{Acknowledgements}

We thank The Research Council of Iran University of Science and Technology (IUST), Tehran, Iran (Grant No 160/19108) for their support. We would also like to acknowledge the support of Iran Nanotechnology Initiative Council (INIC), Iran.

\section{References}

1 Li, C.-J. \& Anastas, P. T. Green Chemistry: present and future. Chemical Society Reviews 41, 1413-1414, doi:10.1039/C1CS90064A (2012).

2 Sheldon, R. A. Metrics of green chemistry and sustainability: past, present, and future. ACS Sustainable Chemistry \& Engineering 6, 32-48 (2018).

3 Erythropel, H. C. et al. The Green ChemisTREE: 20 years after taking root with the 12 principles. Green chemistry 20, 1929-1961 (2018).

4 Ganesh, K. N. et al. Green Chemistry: A Framework for a Sustainable Future. Organic Process Research \& Development 25, 1455-1459, doi:10.1021/acs.oprd.1c00216 (2021).

5 Bilal, M., Zhao, Y., Rasheed, T. \& Iqbal, H. M. Magnetic nanoparticles as versatile carriers for enzymes immobilization: A review. International journal of biological macromolecules 120, 2530-2544 (2018).

6 Gdovinová, V. et al. Memory effect in nematic phase of liquid crystal doped with magnetic and nonmagnetic nanoparticles. Journal of Molecular Liquids 282, 286-291 (2019).

7 Félix, L. L. et al. Gold-decorated magnetic nanoparticles design for hyperthermia applications and as a potential platform for their surface-functionalization. Scientific reports 9, 1-11 (2019).

8 Moghanizadeh, A., Ashrafizadeh, F., Varshosaz, J. \& Ferreira, A. Study the effect of static magnetic field intensity on drug delivery by magnetic nanoparticles. Scientific Reports 11, 1-13 (2021).

9 Bai, C. et al. Synthesis of Ultrasmall Fe304 Nanoparticles as T 1-T 2 Dual-Modal Magnetic Resonance Imaging Contrast Agents in Rabbit Hepatic Tumors. ACS Applied Nano Materials 3, 3585-3595 (2020).

10 Lu, C. et al. Engineering of magnetic nanoparticles as magnetic particle imaging tracers. Chemical Society Reviews (2021).

11 Garanina, A. S. et al. Temperature-controlled magnetic nanoparticles hyperthermia inhibits primary tumor growth and metastases dissemination. Nanomedicine: Nanotechnology, Biology and Medicine 25, 102171 (2020). 
12 Lavorato, G. C., Das, R., Masa, J. A., Phan, M.-H. \& Srikanth, H. Hybrid magnetic nanoparticles as efficient nanoheaters in biomedical applications. Nanoscale Advances 3, 867-888 (2021).

13 Wang, Z., Guo, J., Ma, J. \& Shao, L. Highly regenerable alkali-resistant magnetic nanoparticles inspired by mussels for rapid selective dye removal offer high-efficiency environmental remediation. Journal of Materials Chemistry A 3, 19960-19968 (2015).

14 Saranya, S., Aneeja, T., Neetha, M. \& Anilkumar, G. Recent advances in the iron-catalysed multicomponent reactions. Applied Organometallic Chemistry 34, e5991 (2020).

15 Zhang, Q., Yang, X. \& Guan, J. Applications of magnetic nanomaterials in heterogeneous catalysis. ACS Applied Nano Materials 2, 4681-4697 (2019).

16 Shylesh, S., Schünemann, V. \& Thiel, W. R. Magnetically separable nanocatalysts: bridges between homogeneous and heterogeneous catalysis. Angewandte Chemie International Edition 49, 3428-3459 (2010).

17 Ghereghlou, M., Esmaeili, A. A. \& Darroudi, M. Preparation of Fe304@ C-dots as a recyclable magnetic nanocatalyst using Elaeagnus angustifolia and its application for the green synthesis of formamidines. Applied Organometallic Chemistry, e6387 (2021).

18 Karami, S., Dekamin, M. G., Valiey, E. \& Shakib, P. DABA MNPs: A new and efficient magnetic bifunctional nanocatalyst for the green synthesis of biologically active pyrano [2, 3-c] pyrazole and benzylpyrazolyl coumarin derivatives. New Journal of Chemistry 44, 13952-13961 (2020).

19 Alirezvani, Z., Dekamin, M. G. \& Valiey, E. Cu (II) and magnetite nanoparticles decorated melaminefunctionalized chitosan: A synergistic multifunctional catalyst for sustainable cascade oxidation of benzyl alcohols/Knoevenagel condensation. Scientific reports 9, 1-12 (2019).

20 Simonsen, G., Strand, M. \& Øye, G. Potential applications of magnetic nanoparticles within separation in the petroleum industry. Journal of Petroleum Science and Engineering 165, 488-495 (2018).

21 Zhou, K., Zhou, X., Liu, J. \& Huang, Z. Application of magnetic nanoparticles in petroleum industry: A review. Journal of Petroleum Science and Engineering 188, 106943 (2020).

22 Yeap, S. P., Lim, J., Ooi, B. S. \& Ahmad, A. L. Agglomeration, colloidal stability, and magnetic separation of magnetic nanoparticles: collective influences on environmental engineering applications. Journal of Nanoparticle Research 19, 1-15 (2017).

23 Chen, J. et al. Structural Regulation of Magnetic Polymer Microsphere@ lonic Liquids with an Intermediate Protective Layer and Application as Core-Shell-Shell Catalysts with High Stability and Activity. ACS omega 5, 23062-23069 (2020). 
24 Trifonov, A., Stemmer, A. \& Tel-Vered, R. Carbon-coated magnetic nanoparticles as a removable protection layer extending the operation lifetime of bilirubin oxidase-based bioelectrode.

Bioelectrochemistry 137, 107640 (2021).

25 Martínez-Prieto, L. M. et al. Ultrastable Magnetic Nanoparticles Encapsulated in Carbon for Magnetically Induced Catalysis. ACS Applied Nano Materials 3, 7076-7087, doi:10.1021/acsanm.0c01392 (2020).

26 Ziegler-Borowska, M. Magnetic nanoparticles coated with aminated starch for HSA immobilizationsimple and fast polymer surface functionalization. International journal of biological macromolecules 136, 106-114 (2019).

27 de Mendonça, E. S. D. T. et al. Effects of silica coating on the magnetic properties of magnetite nanoparticles. Surfaces and Interfaces 14, 34-43 (2019).

$28 \mathrm{Gad}$, Y. H. \& Elbarbary, A. M. Radiation synthesis of Fe304/SiO2/glycidyl methacrylate/acrylonitrile nanocomposite for adsorption of basic violet 7 dye: Kinetic, isotherm, and thermodynamic study. Applied Organometallic Chemistry 35, e6258 (2021).

29 Sharma, U. K., Ranjan, P., Van der Eycken, E. V. \& You, S.-L. Sequential and direct multicomponent reaction (MCR)-based dearomatization strategies. Chemical Society Reviews 49, 8721-8748 (2020).

30 Keshavarz, M., Dekamin, M. G., Mamaghani, M. \& Nikpassand, M. Tetramethylguanidinefunctionalized melamine as a multifunctional organocatalyst for the expeditious synthesis of $1,2,4$ triazoloquinazolinones. Scientific reports 11, 1-14 (2021).

31 Slobbe, P., Ruijter, E. \& Orru, R. V. Recent applications of multicomponent reactions in medicinal chemistry. MedChemComm 3, 1189-1218 (2012).

32 Khumalo, M. R., Maddila, S. N., Maddila, S. \& Jonnalagadda, S. B. A multicomponent, facile and catalyst-free microwave-assisted protocol for the synthesis of pyrazolo-[3, 4-b]-quinolines under green conditions. RSC advances 9, 30768-30772 (2019).

33 Ebrahimiasl, H., Azarifar, D., Rakhtshah, J., Keypour, H. \& Mahmoudabadi, M. Application of novel and reusable Fe304@Coll (macrocyclic Schiff base ligand) for multicomponent reactions of highly substituted thiopyridine and 4H-chromene derivatives. Applied Organometallic Chemistry 34, e5769 (2020).

34 Dekamin, M. G., Azimoshan, M. \& Ramezani, L. Chitosan: a highly efficient renewable and recoverable bio-polymer catalyst for the expeditious synthesis of a-amino nitriles and imines under mild conditions. Green Chemistry 15, 811-820 (2013).

35 Alirezvani, Z., Dekamin, M. G. \& Valiey, E. New Hydrogen-Bond-Enriched 1, 3, 5-Tris (2-hydroxyethyl) Isocyanurate Covalently Functionalized MCM-41: An Efficient and Recoverable Hybrid Catalyst for 
Convenient Synthesis of Acridinedione Derivatives. ACS omega 4, 20618-20633 (2019).

36 Valiey, E., Dekamin, M. G. \& Alirezvani, Z. Melamine-modified chitosan materials: An efficient and recyclable bifunctional organocatalyst for green synthesis of densely functionalized bioactive dihydropyrano [2, 3-c] pyrazole and benzylpyrazolyl coumarin derivatives. International journal of biological macromolecules 129, 407-421 (2019).

37 Akbari, A., Dekamin, M. G., Yaghoubi, A. \& Naimi-Jamal, M. R. Novel magnetic propylsulfonic acidanchored isocyanurate-based periodic mesoporous organosilica (Iron oxide@ PMO-ICS-PrSO 3 H) as a highly efficient and reusable nanoreactor for the sustainable synthesis of imidazopyrimidine derivatives. Scientific Reports 10, 1-16 (2020).

38 John, S. E., Gulati, S. \& Shankaraiah, N. Recent advances in multi-component reactions and their mechanistic insights: a triennium review. Organic Chemistry Frontiers (2021).

39 Cioc, R. C., Ruijter, E. \& Orru, R. V. Multicomponent reactions: advanced tools for sustainable organic synthesis. Green Chemistry 16, 2958-2975 (2014).

40 Basu, S., Chatterjee, S., Bhaumik, A. \& Mukhopadhyay, C. Ultrasound-promoted novel route to triazabenzo [b] cyclopenta [Im] fluorenes: An efficient NiFe204@ SiO2-SO3H nanocatalyst-assisted green synthesis. Applied Organometallic Chemistry, e6426.

41 Abbaspour-Gilandeh, E., Yahyazadeh, A. \& Aghaei-Hashjin, M. One-pot synthesis of 3, 4dihydropyrimidin-2 $(1 \mathrm{H})$-ones catalyzed by SO $3 \mathrm{H} @$ imineZCMNPs as a novel, efficient and reusable acidic nanocatalyst under solvent-free conditions. RSC advances 8, 40243-40251 (2018).

42 Essid, I., Lahbib, K., Kaminsky, W., Nasr, C. B. \& Touil, S. 5-phosphonato-3, 4-dihydropyrimidin-2 (1H)ones: Zinc triflate-catalyzed one-pot multi-component synthesis, X-ray crystal structure and antiinflammatory activity. Journal of Molecular Structure 1142, 130-138 (2017).

43 Meng, F.-J., Shi, L., Feng, G.-S., Sun, L. \& Zhou, Y.-G. Enantioselective Synthesis of 3, 4Dihydropyrimidin-2 $(1 \mathrm{H})$-ones through Organocatalytic Transfer Hydrogenation of 2-Hydroxypyrimidines. The Journal of organic chemistry 84, 4435-4442 (2019).

44 Aher, D. S., Khillare, K. R., Chavan, L. D. \& Shankarwar, S. G. Tungsten-substituted molybdophosphoric acid impregnated with kaolin: effective catalysts for the synthesis of 3, 4-dihydropyrimidin-2 (1 H)-ones via biginelli reaction. RSC Advances 11, 2783-2792 (2021).

45 Matias, M. et al. Potential antitumoral 3, 4-dihydropyrimidin-2-(1 H)-ones: Synthesis, in vitro biological evaluation and QSAR studies. RSC advances 6, 84943-84958 (2016).

46 Venkatapathy, K., Magesh, C., Lavanya, G., Perumal, P. \& Sathishkumar, R. A nanocrystalline CdS thin film as a heterogeneous, recyclable catalyst for effective synthesis of dihydropyrimidinones and a new 
class of carbazolyl dihydropyrimidinones via an improved Biginelli protocol. New Journal of Chemistry 43, 10989-11002 (2019).

47 Shaabani, A., Bazgir, A. \& Teimouri, F. Ammonium chloride-catalyzed one-pot synthesis of 3,4dihydropyrimidin-2-(1H)-ones under solvent-free conditions. Tetrahedron Letters 44, 857-859, doi:https://doi.org/10.1016/S0040-4039(02)02612-6 (2003).

48 Patil, R. V., Chavan, J. U., Dalal, D. S., Shinde, V. S. \& Beldar, A. G. Biginelli reaction: polymer supported catalytic approaches. ACS combinatorial science 21, 105-148 (2019).

49 Yao, B.-J., Wu, W.-X., Ding, L.-G. \& Dong, Y.-B. Sulfonic Acid and Ionic Liquid Functionalized Covalent Organic Framework for Efficient Catalysis of the Biginelli Reaction. The Journal of Organic Chemistry 86, 3024-3032 (2021).

50 Freitas, E. F. et al. Tuning the Biginelli reaction mechanism by the ionic liquid effect: the combined role of supported heteropolyacid derivatives and acidic strength. RSC advances $\mathbf{9}, 27125-27135$ (2019).

51 Shaabani, A., Sarvary, A., Rahmati, A. \& Rezayan, A. H. Ionic Liquid/Silica Sulfuric Acid Promoted Fast Synthesis of a Biginelli-Like Scaffold Reaction. Letters in Organic Chemistry 4, 68-71, doi:http://dx.doi.org/10.2174/157017807780037531 (2007).

52 Verma, A., De, D., Tomar, K. \& Bharadwaj, P. K. An amine functionalized metal-organic framework as an effective catalyst for conversion of $\mathrm{CO} 2$ and Biginelli reactions. Inorganic chemistry 56, 9765-9771 (2017).

53 Patel, U., Parmar, B., Patel, P., Dadhania, A. \& Suresh, E. The synthesis and characterization of Zn (ii)/Cd (ii) based MOFs by a mixed ligand strategy: a Zn (ii) MOF as a dual functional material for reversible dye adsorption and as a heterogeneous catalyst for the Biginelli reaction. Materials Chemistry Frontiers 5, 304-314 (2021).

54 Phukan, A. et al. An efficient and robust heterogeneous mesoporous montmorillonite clay catalyst for the Biginelli type reactions. Advanced Powder Technology 28, 1585-1592 (2017).

55 Sheykhan, M., Yahyazadeh, A. \& Ramezani, L. A novel cooperative Lewis acid/Brønsted base catalyst Fe304@ SiO2-APTMS-Fe (OH) 2: An efficient catalyst for the Biginelli reaction. Molecular Catalysis 435, 166-173 (2017).

$56 \mathrm{Li}, \mathrm{N}$. et al. Air-stable zirconium (IV)-salophen perfluorooctanesulfonate as a highly efficient and reusable catalyst for the synthesis of 3, 4-dihydropyrimidin-2-(1H)-ones/thiones under solvent-free conditions. Applied Organometallic Chemistry 34, e5454 (2020).

57 Khatri, C. K., Rekunge, D. S. \& Chaturbhuj, G. U. Sulfated polyborate: a new and eco-friendly catalyst for one-pot multi-component synthesis of 3, 4-dihydropyrimidin-2 $(1 \mathrm{H})$-ones/thiones via Biginelli reaction. New Journal of Chemistry 40, 10412-10417 (2016). 
58 Dekamin, M. G., Mehdipoor, F. \& Yaghoubi, A. 1, 3, 5-Tris (2-hydroxyethyl) isocyanurate functionalized graphene oxide: a novel and efficient nanocatalyst for the one-pot synthesis of 3, 4-dihydropyrimidin-2 (1 H)-ones. New Journal of Chemistry 41, 6893-6901 (2017).

59 Wang, Y. T., Tang, G. M. \& Wu, Y. S. A Set of phenyl sulfonate metal coordination complexes triggered Biginelli reaction for the high efficient synthesis of 3, 4-dihydropyrimidin-2 (1H)-ones under solvent-free conditions. Applied Organometallic Chemistry 34, e5542 (2020).

60 Valiey, E., Dekamin, M. G. \& Alirezvani, Z. Sulfamic acid pyromellitic diamide-functionalized MCM-41 as a multifunctional hybrid catalyst for melting-assisted solvent-free synthesis of bioactive 3, 4dihydropyrimidin-2-(1 H)-ones. Scientific Reports 11, 1-15 (2021).

61 Nasresfahani, Z. \& Kassaee, M. Z. Cu (II) immobilized on mesoporous organosilica as an efficient and reusable nanocatalyst for one-pot Biginelli reaction under solvent-free conditions. Applied Organometallic Chemistry 32, e4106 (2018).

62 Safaei-Ghomi, J., Tavazo, M. \& Mahdavinia, G. H. Ultrasound promoted one-pot synthesis of 3, 4dihydropyrimidin-2 $(1 \mathrm{H})$-ones/thiones using dendrimer-attached phosphotungstic acid nanoparticles immobilized on nanosilica. Ultrasonics sonochemistry 40, 230-237 (2018).

63 Kęciek, A., Paprocki, D., Koszelewski, D. \& Ostaszewski, R. Evaluation of alcohols as substrates for the synthesis of 3, 4-dihydropyrimidin-2 $(1 \mathrm{H})$-ones under environmentally friendly conditions. Catalysis Communications 135, 105887 (2020).

64 Yu, T., Xue, Z., Zhao, X., Chen, W. \& Mu, T. Green synthesis of porous $\beta$-cyclodextrin polymers for rapid and efficient removal of organic pollutants and heavy metal ions from water. New Journal of Chemistry 42, 16154-16161 (2018).

65 Zhang, K. et al. EDTA-based adsorbents for the removal of metal ions in wastewater. Coordination Chemistry Reviews 434, 213809 (2021).

66 Danesh, N., Ghorbani, M. \& Marjani, A. Separation of copper ions by nanocomposites using adsorption process. Scientific Reports 11, 1-23 (2021).

67 Zhao, F. et al. One-pot synthesis of trifunctional chitosan-EDTA- $\beta$-cyclodextrin polymer for simultaneous removal of metals and organic micropollutants. Scientific reports 7, 1-14 (2017).

68 Tong, W. H. Comment on "Pharmacodynamics of cerebrospinal fluid asparagine after asparaginase". Cancer Chemotherapy and Pharmacology, 1-2 (2021).

69 Wang, X. et al. Microwave-assisted synthesis, characterization, cell imaging of fluorescent carbon dots using l-asparagine as precursor. New Journal of Chemistry 43, 3323-3331 (2019). 
70 Saikia, G. et al. Polymer immobilized tantalum (v)-amino acid complexes as selective and recyclable heterogeneous catalysts for oxidation of olefins and sulfides with aqueous $\mathrm{H} 2 \mathrm{O} 2$. New Journal of Chemistry 43, 17251-17266 (2019).

$71 \mathrm{Jin}, \mathrm{C}$. et al. Magnetic iron oxide nanoparticles coated by hierarchically structured silica: a highly stable nanocomposite system and ideal catalyst support. 2, 11202-11208 (2014).

72 An, F. \& Gao, B. J. J. o. h. m. Chelating adsorption properties of PEl/SiO2 for plumbum ion. 145, 495500 (2007).

73 Kargar, S., Elhamifar, D. \& Zarnegaryan, A. Core-shell structured Fe304@ SiO2-supported IL/[Mo6019]: A novel and magnetically recoverable nanocatalyst for the preparation of biologically active dihydropyrimidinones. Journal of Physics and Chemistry of Solids 146, 109601 (2020).

74 Safari, J. \& Gandomi-Ravandi, S. Titanium dioxide supported on MWCNTs as an eco-friendly catalyst in the synthesis of 3, 4-dihydropyrimidin-2-(1 H)-ones accelerated under microwave irradiation. New Journal of Chemistry 38, 3514-3521 (2014).

75 Bairagi, K. M. et al. Larvicidal study of tetrahydropyrimidine scaffolds against Anopheles arabiensis and structural insight by single crystal X-ray studies. Chemical biology \& drug design 92, 1924-1932 (2018).

76 Majellaro, M. et al. 3, 4-Dihydropyrimidin-2 (1 H)-ones as Antagonists of the Human A2B Adenosine Receptor: Optimization, Structure-Activity Relationship Studies, and Enantiospecific Recognition. Journal of Medicinal Chemistry (2020).

77 Esmaeili, R., Kafi-Ahmadi, L. \& Khademinia, S. A highly efficient one-pot multicomponent synthesis of 3, 4-dihydropyrimidin-2-(1H)-ones/thiones catalyzed by strontium pyroarsenate nano-plates. Journal of Molecular Structure 1216, 128124 (2020).

78 do Nascimento, L. G. et al. Niobium oxides as heterogeneous catalysts for Biginelli multicomponent reaction. The Journal of Organic Chemistry 85, 11170-11180 (2020).

79 Dunn, P. J., Galvin, S. \& Hettenbach, K. The development of an environmentally benign synthesis of sildenafil citrate $\left(\right.$ Viagra $\left.^{\mathrm{T} M}\right)$ and its assessment by Green Chemistry metrics. Green chemistry 6, 43-48 (2004).

80 Singh, P., Yadav, P., Mishra, A. \& Awasthi, S. K. Green and mechanochemical one-pot multicomponent synthesis of bioactive 2-amino-4 H-benzo [b] pyrans via highly efficient amine-functionalized SiO2@ Fe304 nanoparticles. ACS omega 5, 4223-4232 (2020).

81 Constable, D. J., Curzons, A. D. \& Cunningham, V. L. Metrics to 'green'chemistry-which are the best? Green Chemistry 4, 521-527 (2002). 
82 Zamani, F. \& Izadi, E. Synthesis and characterization of sulfonated-phenylacetic acid coated Fe304 nanoparticles as a novel acid magnetic catalyst for Biginelli reaction. Catalysis Communications 42, 104108 (2013).

83 Wang, B., Wei, Q. \& Qu, S. Synthesis and characterization of uniform and crystalline magnetite nanoparticles via oxidation-precipitation and modified co-precipitation methods. Int. J. Electrochem. Sci $\mathbf{8}$, 3786-3793 (2013).

84 Stöber, W., Fink, A. \& Bohn, E. Controlled growth of monodisperse silica spheres in the micron size range. Journal of colloid and interface science 26, 62-69 (1968).

85 Jafarzadeh, M., Soleimani, E., Norouzi, P., Adnan, R. \& Sepahvand, H. Preparation of trifluoroacetic acid-immobilized Fe304@SiO2-APTES nanocatalyst for synthesis of quinolines. Journal of Fluorine Chemistry 178, 219-224 (2015).

86 Repo, E., Kurniawan, T. A., Warchol, J. K. \& Sillanpää, M. E. Removal of Co (II) and Ni (II) ions from contaminated water using silica gel functionalized with EDTA and/or DTPA as chelating agents. Journal of hazardous materials 171, 1071-1080 (2009).

\section{Tables}

Table 1. Optimization of conditions in the model reaction of urea (2), 4-chlorobenzaldehyde (3a), ethyl acetoacetate (4a), under different conditions in the presence of $\mathrm{Fe}_{3} \mathrm{O}_{4} @ \mathrm{SiO}_{2}$-APTS-EDTA-asparagine nanocatalyst (1). ${ }^{\text {a }}$<smiles>NC([NH3+])=O</smiles>

2<smiles>O=Cc1ccc(Cl)cc1</smiles>

$3 a$

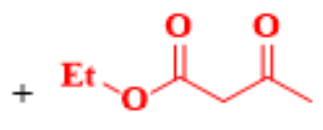

$4 a$

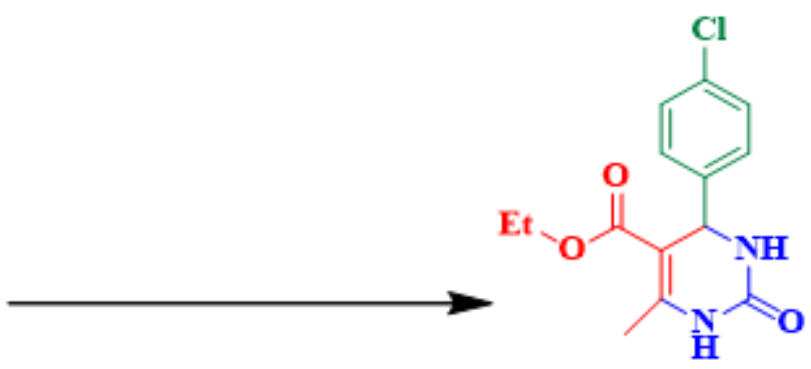

5 a 


\begin{tabular}{|c|c|c|c|c|c|}
\hline Entry & Catalyst & Solvent & $\begin{array}{l}\text { Temperature } \\
\left({ }^{\circ} \mathrm{C}\right)\end{array}$ & $\begin{array}{l}\text { Time } \\
(\min )\end{array}$ & $\begin{array}{l}\text { Yield }{ }^{b}(\%) \\
5 a\end{array}$ \\
\hline 1 & - & Solvent-free & r.t & 30 & Trace \\
\hline 2 & $\begin{array}{l}\mathrm{Fe}_{3} \mathrm{O}_{4} @ \mathrm{SiO}_{2}-\mathrm{APTS}-\mathrm{EDTA}- \\
\text { asparagine }\end{array}$ & Solvent-free & r.t & 30 & 85 \\
\hline 3 & $\begin{array}{l}\mathrm{Fe}_{3} \mathrm{O}_{4} @ \mathrm{SiO}_{2}-\mathrm{APTS}-\mathrm{EDTA}- \\
\text { asparagine }\end{array}$ & Solvent-free & 60 & 20 & 95 \\
\hline 4 & $\begin{array}{l}\mathrm{Fe}_{3} \mathrm{O}_{4} @ \mathrm{SiO}_{2}-\mathrm{APTS}-\mathrm{EDTA}- \\
\text { asparagine }\end{array}$ & $\mathrm{EtOH}$ & r.t & 20 & 65 \\
\hline 5 & $\begin{array}{l}\mathrm{Fe}_{3} \mathrm{O}_{4} @ \mathrm{SiO}_{2}-\mathrm{APTS}-\mathrm{EDTA}- \\
\text { asparagine }\end{array}$ & $\mathrm{EtOH}$ & Reflux & 20 & 85 \\
\hline 6 & $\begin{array}{l}\mathrm{Fe}_{3} \mathrm{O}_{4} @ \mathrm{SiO}_{2}-\mathrm{APTS}-\mathrm{EDTA}- \\
\text { asparagine }\end{array}$ & $\mathrm{MeOH}$ & r.t & 40 & 45 \\
\hline 7 & $\begin{array}{l}\mathrm{Fe}_{3} \mathrm{O}_{4} @ \mathrm{SiO}_{2}-\mathrm{APTS} \text {-EDTA- } \\
\text { asparagine }\end{array}$ & $\mathrm{MeOH}$ & Reflux & 40 & 55 \\
\hline 8 & $\begin{array}{l}\mathrm{Fe}_{3} \mathrm{O}_{4} @ \mathrm{SiO}_{2}-\mathrm{APTS}-\mathrm{EDTA}- \\
\text { asparagine }\end{array}$ & $\mathrm{H}_{2} \mathrm{O}$ & r.t & 30 & 60 \\
\hline 9 & $\begin{array}{l}\mathrm{Fe}_{3} \mathrm{O}_{4} @ \mathrm{SiO}_{2}-\mathrm{APTS} \text {-EDTA- } \\
\text { asparagine }\end{array}$ & $\mathrm{H}_{2} \mathrm{O}$ & Reflux & 30 & 65 \\
\hline 10 & $\begin{array}{l}\mathrm{Fe}_{3} \mathrm{O}_{4} @ \mathrm{SiO}_{2}-\mathrm{APTS}-\mathrm{EDTA}- \\
\text { asparagine }\end{array}$ & $\begin{array}{l}\mathrm{EtOH} / \mathrm{H}_{2} \mathrm{O} \\
(1: 1)\end{array}$ & r.t & 20 & 63 \\
\hline 11 & $\begin{array}{l}\mathrm{Fe}_{3} \mathrm{O}_{4} @ \mathrm{SiO}_{2}-\mathrm{APTS}-\mathrm{EDTA}- \\
\text { asparagine }\end{array}$ & $\begin{array}{l}\mathrm{EtOH} / \mathrm{H}_{2} \mathrm{O} \\
(1: 1)\end{array}$ & Reflux & 20 & 70 \\
\hline 12 & $\begin{array}{l}\mathrm{Fe}_{3} \mathrm{O}_{4} @ \mathrm{SiO}_{2}-\mathrm{APTS}-\mathrm{EDTA}- \\
\text { asparagine }\end{array}$ & DMF & r.t & 30 & 55 \\
\hline 13 & $\begin{array}{l}\mathrm{Fe}_{3} \mathrm{O}_{4} @ \mathrm{SiO}_{2}-\mathrm{APTS}-\mathrm{EDTA}- \\
\text { asparagine }\end{array}$ & DMF & Reflux & 30 & 65 \\
\hline 14 & EDTA & Solvent-free & 60 & 20 & 75 \\
\hline 15 & Asparagine & Solvent-free & 60 & 20 & 65 \\
\hline
\end{tabular}

aReaction conditions: urea $(2,1 \mathrm{mmol})$, 4-chlorobenzaldehyde $(3 \mathrm{a}, 1 \mathrm{mmol})$, ethyl acetoacetate $(4 \mathrm{a}, 1$ mmol), $\mathrm{Fe}_{3} \mathrm{O}_{4} @ \mathrm{SiO}_{2}$-APTS-EDTA-asparagine (1) and solvent (3 mL, if not otherwise stated). ${ }^{b}$ Isolated yield.

Due to technical limitations, table 2 is only available as a download in the Supplemental Files section. 
Table 3 Measurement of green chemistry metrics for compound $\mathbf{5 a}$

\begin{tabular}{llll} 
Entry & Parameters of the green approach & Ideal value & Calculated values \\
\hline 1 & E factor & 0 & 0.16 \\
\hline 2 & Atom economy (AE \%) & $100 \%$ & $89.1 \%$ \\
\hline 3 & Carbon efficiency (CE \%) & $100 \%$ & $96 \%$ \\
\hline 4 & Process mass intensity (PMI) & 1 & 1.16 \\
\hline 5 & Reaction mass efficiency (RME \%) & $100 \%$ & $85.5 \%$ \\
\hline
\end{tabular}

Table 4. Comparative results of catalysts for the synthesis of $\mathbf{5 a}$

\begin{tabular}{|c|c|c|c|c|c|}
\hline Entry & Catalyst & $\begin{array}{l}\text { Catalyst } \\
\text { loading }\end{array}$ & $\begin{array}{l}\text { Reaction } \\
\text { conditions }\end{array}$ & $\begin{array}{l}\text { Time } \\
(\min )\end{array}$ & Yield (\%) \\
\hline 1 & $\mathrm{Zn}(\mathrm{II})$-framework & 10 wt $\%$ & $\begin{array}{l}\text { Solvent- } \\
\text { free } / 60^{\circ} \mathrm{C}\end{array}$ & 120 & $91^{52}$ \\
\hline 2 & PANI-FeCl 3 & $200 \mathrm{mg}$ & $\begin{array}{l}\mathrm{CH}_{3} \mathrm{CN} / \\
\text { Reflux }\end{array}$ & 1440 & $83^{82}$ \\
\hline 3 & MCM-41-APS-PMDANHSO ${ }_{3} \mathrm{H}$ & $15 \mathrm{mg}$ & $\begin{array}{l}\text { Solvent- } \\
\text { free } / 80^{\circ} \mathrm{C}\end{array}$ & 35 & $96^{60}$ \\
\hline 4 & $\mathrm{Fe}_{3} \mathrm{O}_{4} @ \mathrm{SiO}_{2}-\mathrm{APTMS}-\mathrm{Fe}(\mathrm{OH})_{2}$ & $10 \mathrm{mg}$ & Neat $/ 80^{\circ} \mathrm{C}$ & 15 & $95^{55}$ \\
\hline 5 & $\begin{array}{l}\text { zirconium (IV)-salophen } \\
\text { perfluorooctanesulfonate }\end{array}$ & $0.05 \mathrm{mmol}$ & $\begin{array}{l}\text { Solvent- } \\
\text { free } / 90^{\circ} \mathrm{C}\end{array}$ & 30 & $96^{56}$ \\
\hline 6 & $\mathrm{Fe}_{3} \mathrm{O}_{4} @ \mathrm{SiO}_{2}$-APTS-EDTA-asparagine & $10 \mathrm{mg}$ & $\begin{array}{l}\text { Solvent- } \\
\text { free } / 60^{\circ} \mathrm{C}\end{array}$ & 20 & $\begin{array}{l}95 \text { This } \\
\text { work }\end{array}$ \\
\hline
\end{tabular}

\section{Figures}



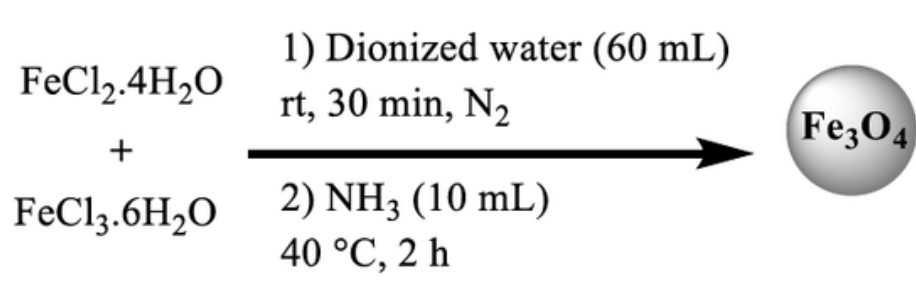

1) $\mathrm{EtOH} / \mathrm{NH}_{3}$

Sonication, $30 \mathrm{~min}$

2) $\mathrm{EtOH} / \mathrm{TEOS}$

$60^{\circ} \mathrm{C}, 24 \mathrm{~h}$

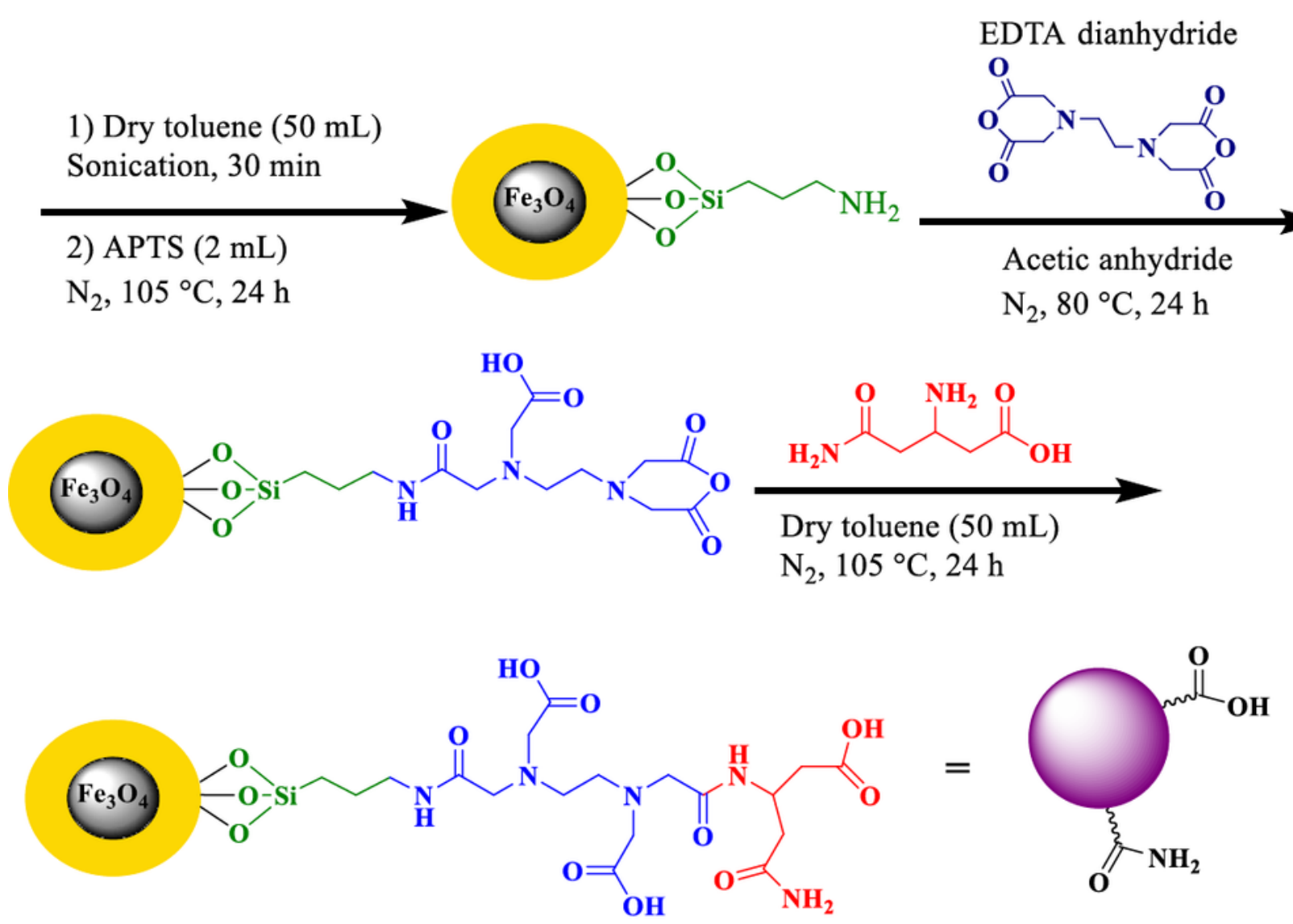

$\mathrm{Fe}_{3} \mathrm{O}_{4} @ \mathrm{SiO}_{2}$-APTS-EDTA-asparagine (1)

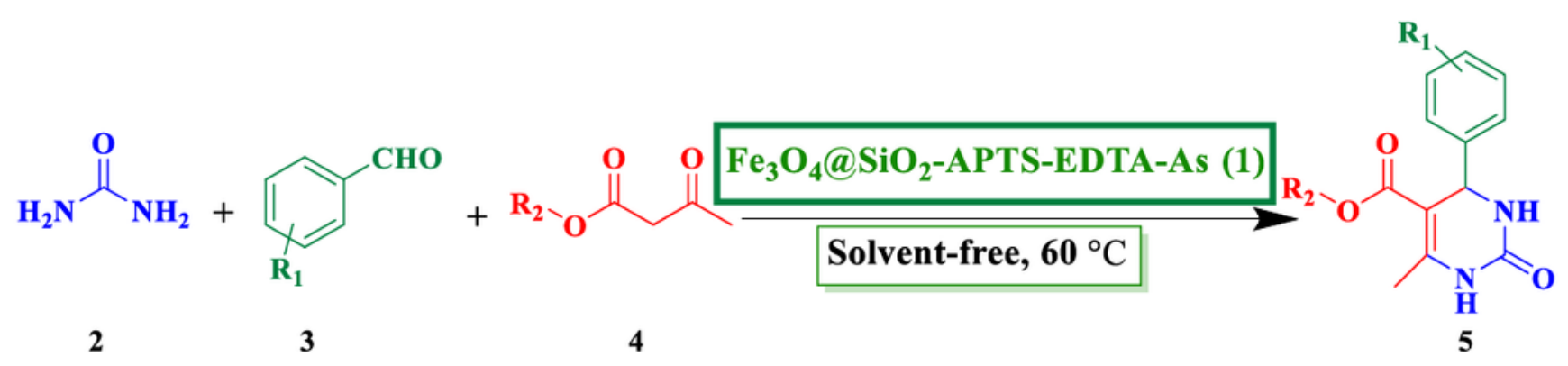

\section{Figure 1}

Schematic preparation of Fe304@SiO2-APTS-EDTA-asparagine (1), as a heterogeneous nanocatalyst, for the synthesis of 3,4-dihydropyrimidin-2(1H)-one 5 derivatives. 


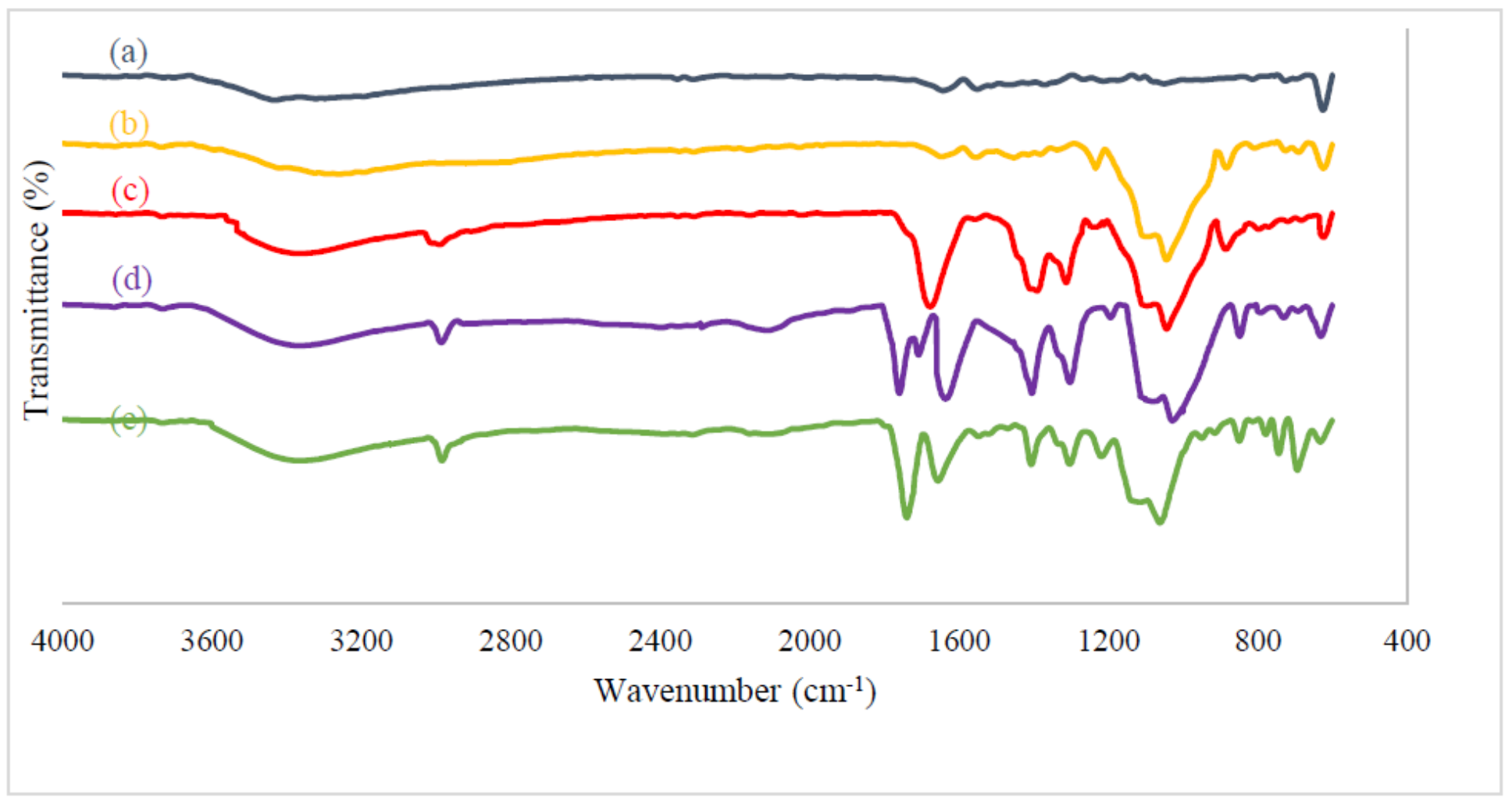

Figure 2

FT-IR spectra of the Fe304 (a), Fe304@SiO2 (b), Fe304@SiO2-APTS (c), Fe304@SiO2-APTS-EDTA (d) and Fe304@Si02-APTS-EDTA-asparagine (1, e). 


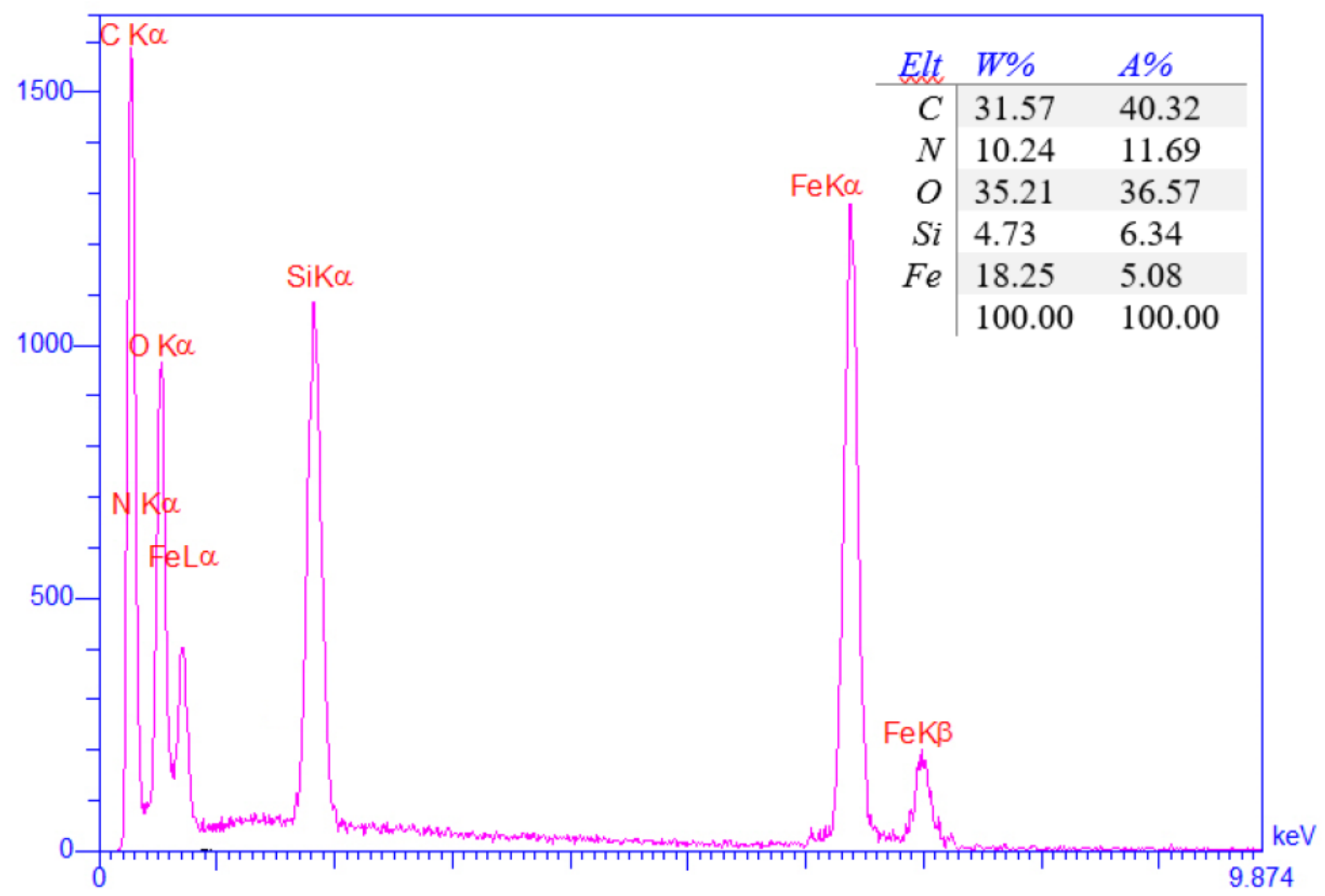

Figure 3

The EDX spectra of the magnetic Fe304@SiO2-APTS-EDTA-asparagine nanomaterial (1). 

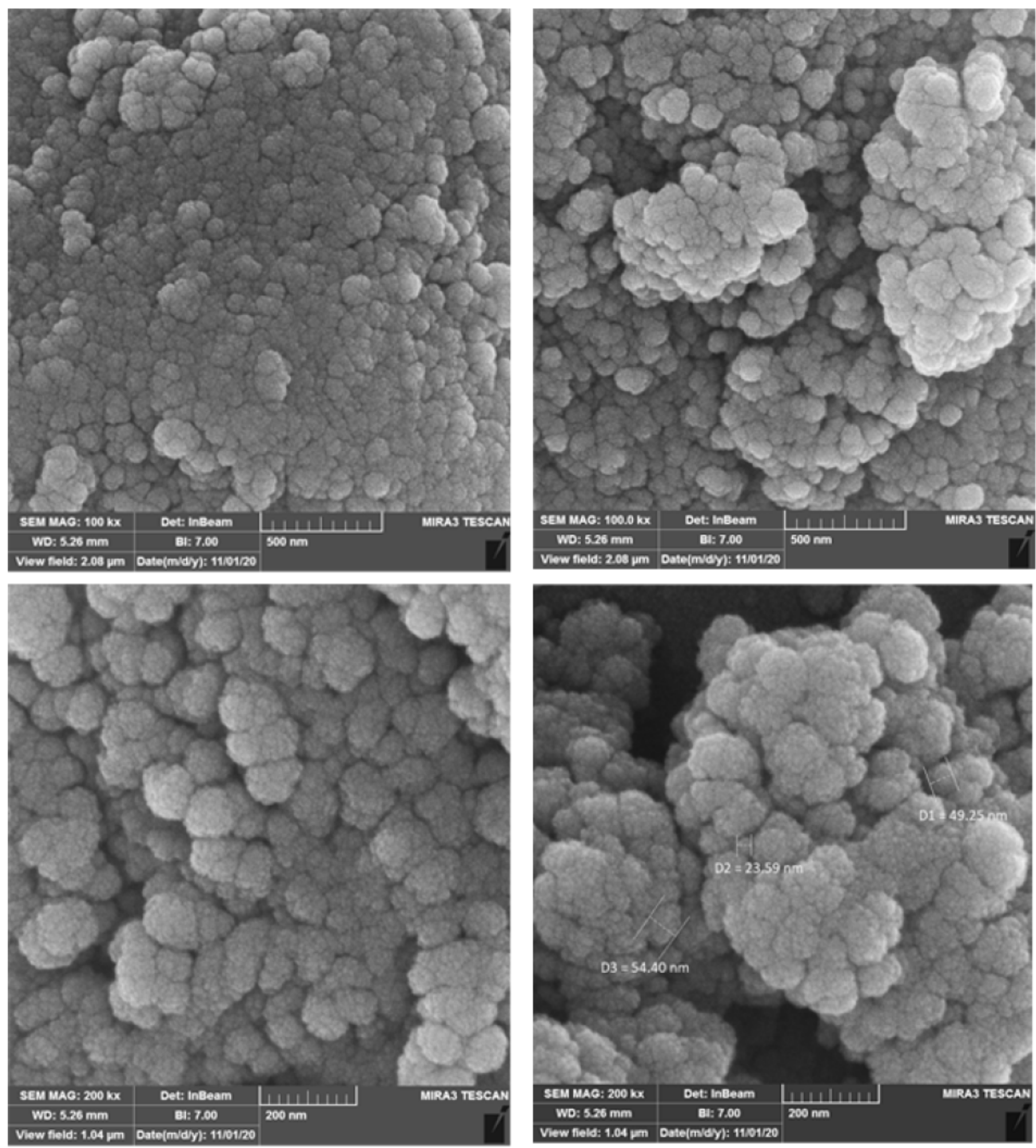

\section{Figure 4}

FESEM images of the magnetic Fe304@SiO2-APTS-EDTA-asparagine nanocatalyst (1). 

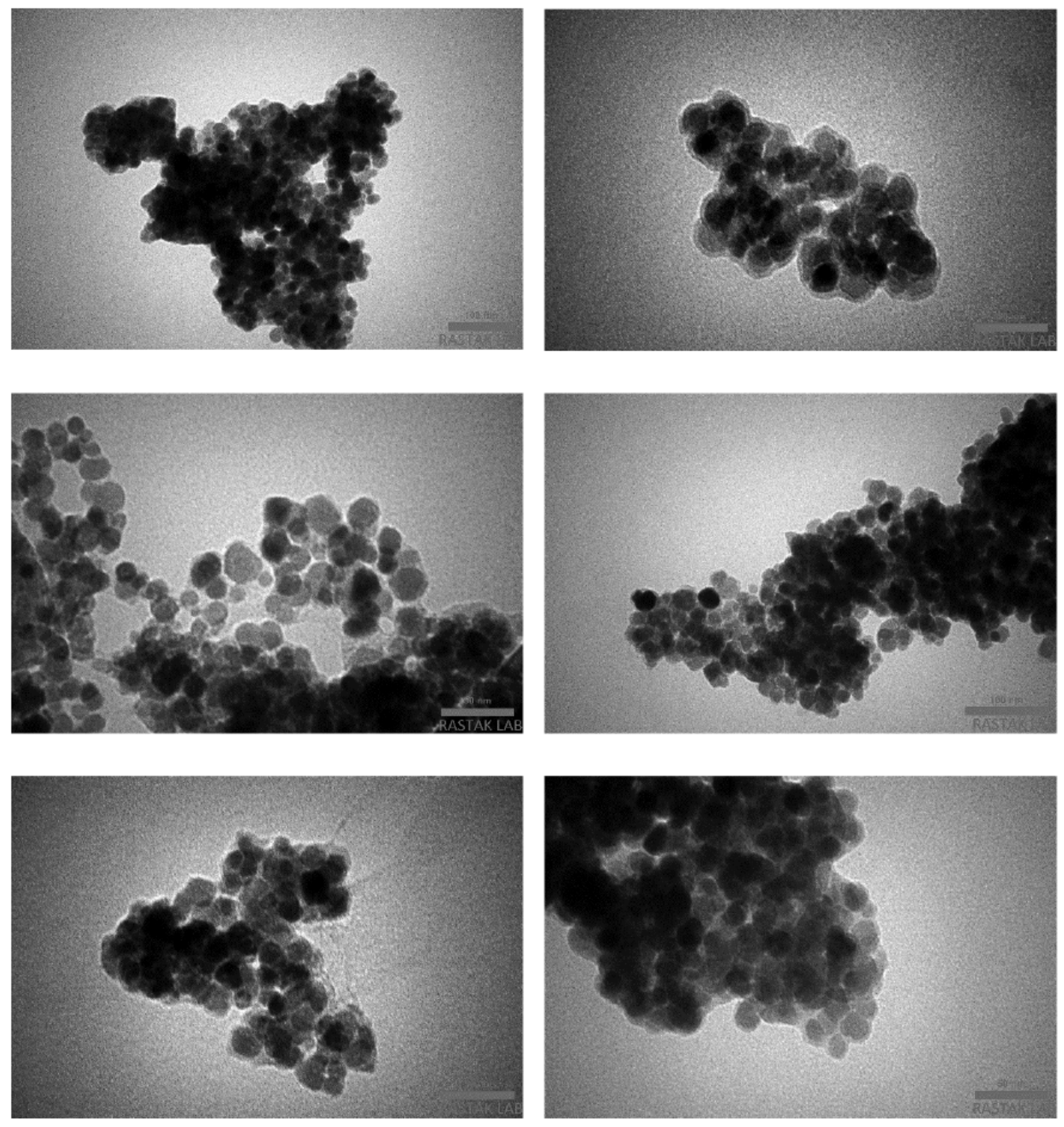

\section{Figure 5}

TEM images of the magnetic Fe304@SiO2-APTS-EDTA-asparagine nanomaterial (1). 

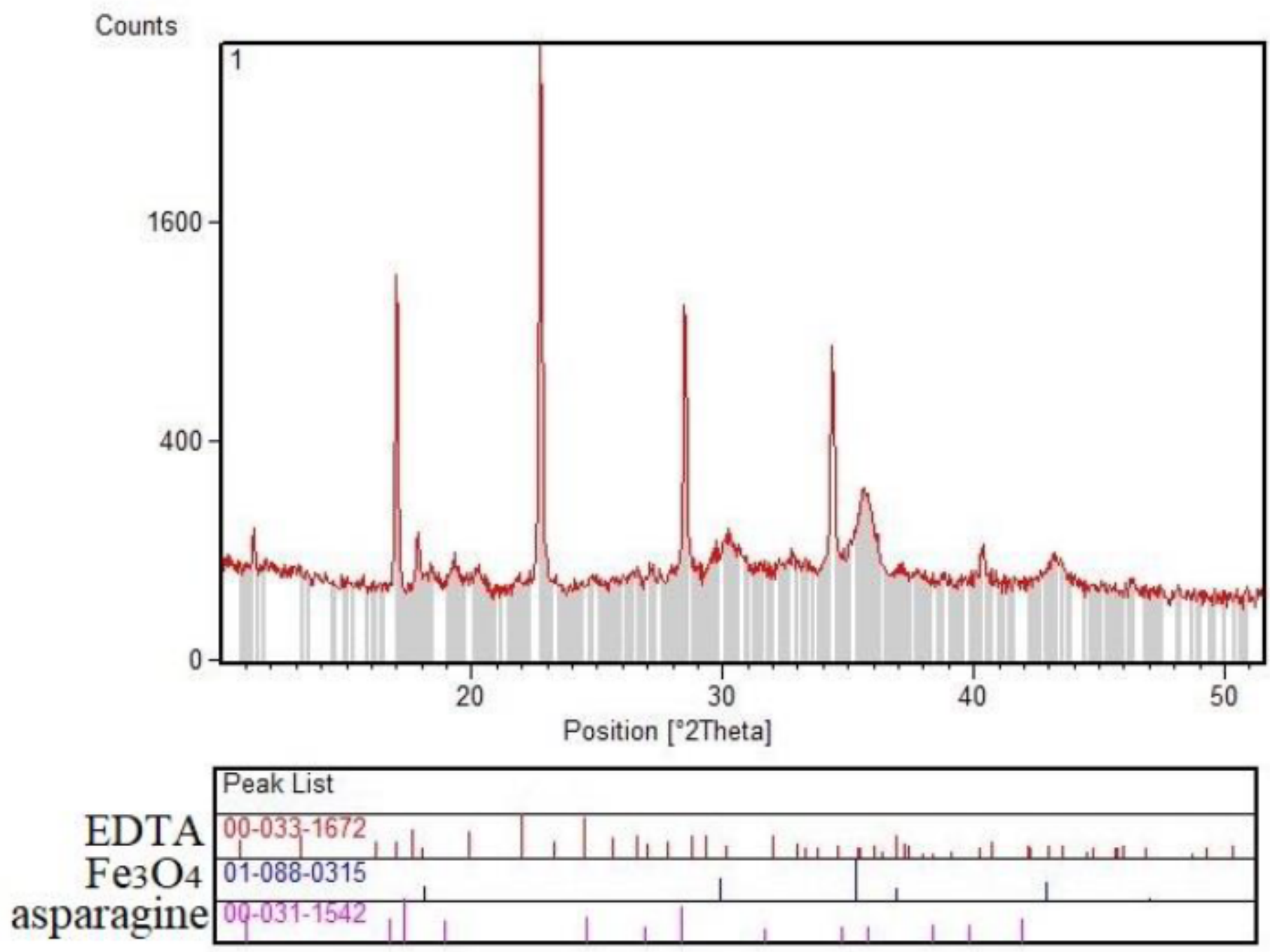

Figure 6

XRD patterns of the magnetic Fe304@SiO2-APTS-EDTA-asparagine nanocatalyst (1). 


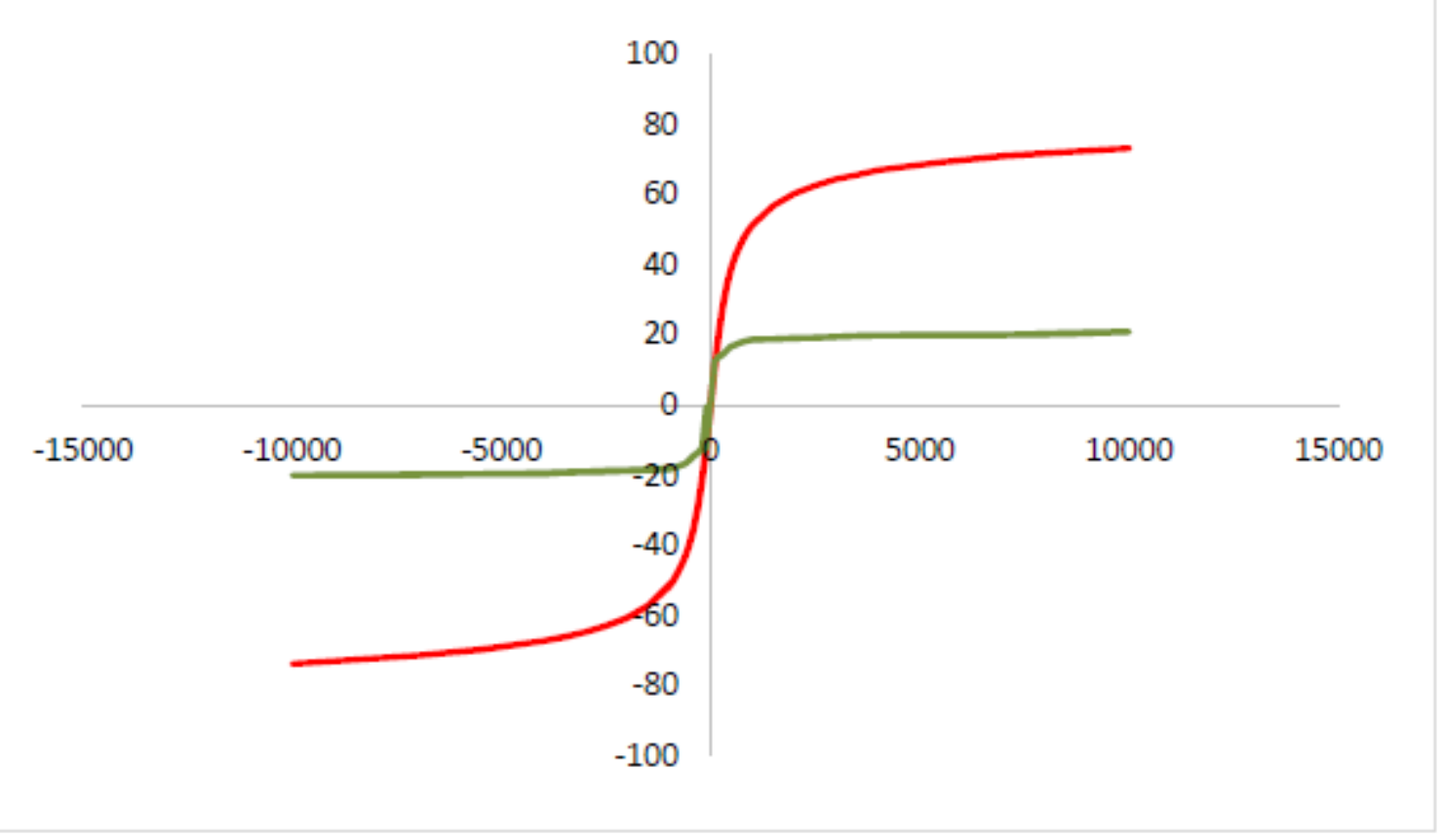

\section{Figure 7}

VSM pattern of Fe304 (red curve) and magnetic Fe304@SiO2-APTS-EDTA-asparagine nanocatalyst (1, green curve).

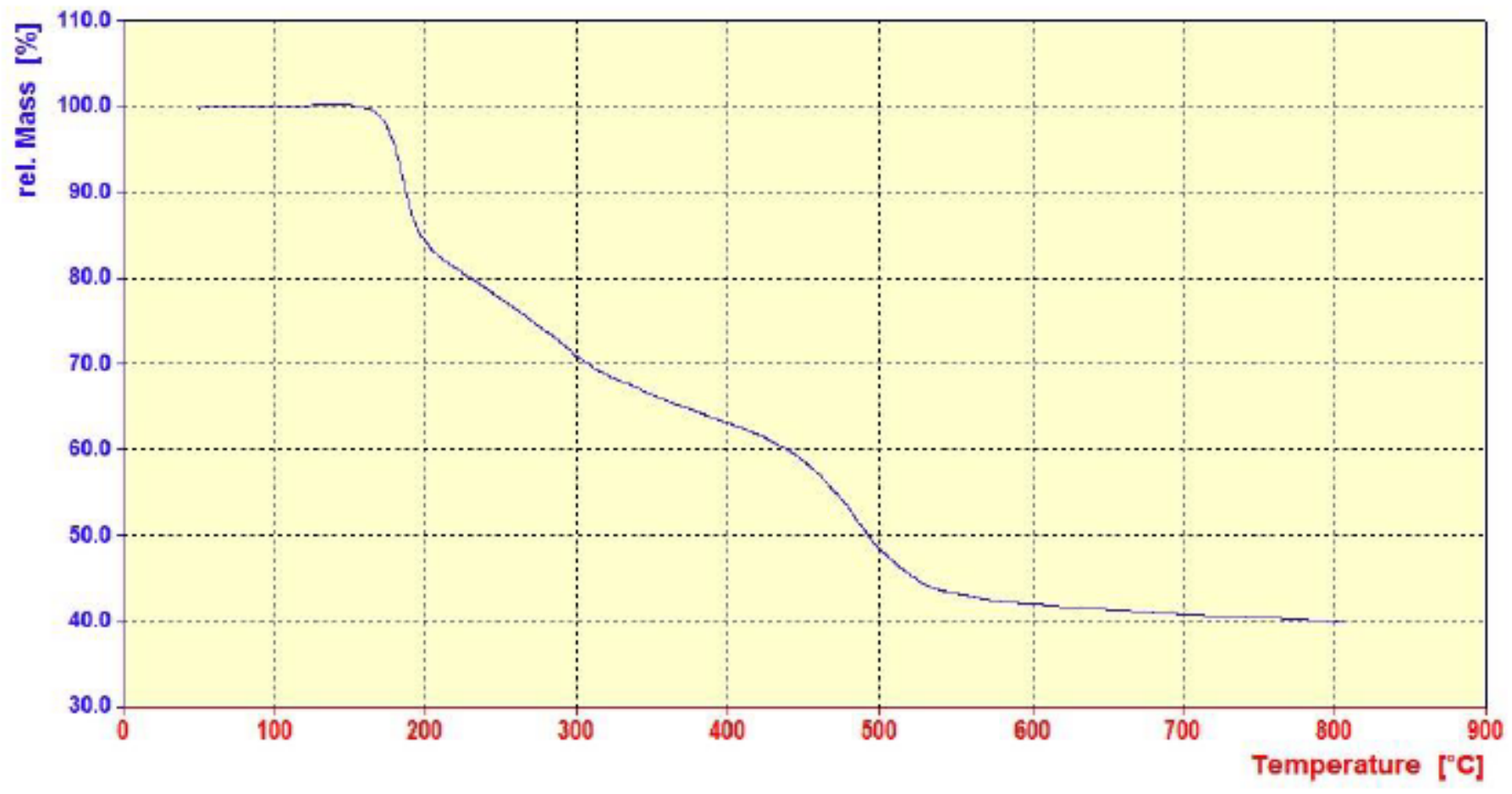

\section{Figure 8}

TGA curve of the magnetic Fe304@SiO2-APTS-EDTA-asparagine nanomaterial (1). 


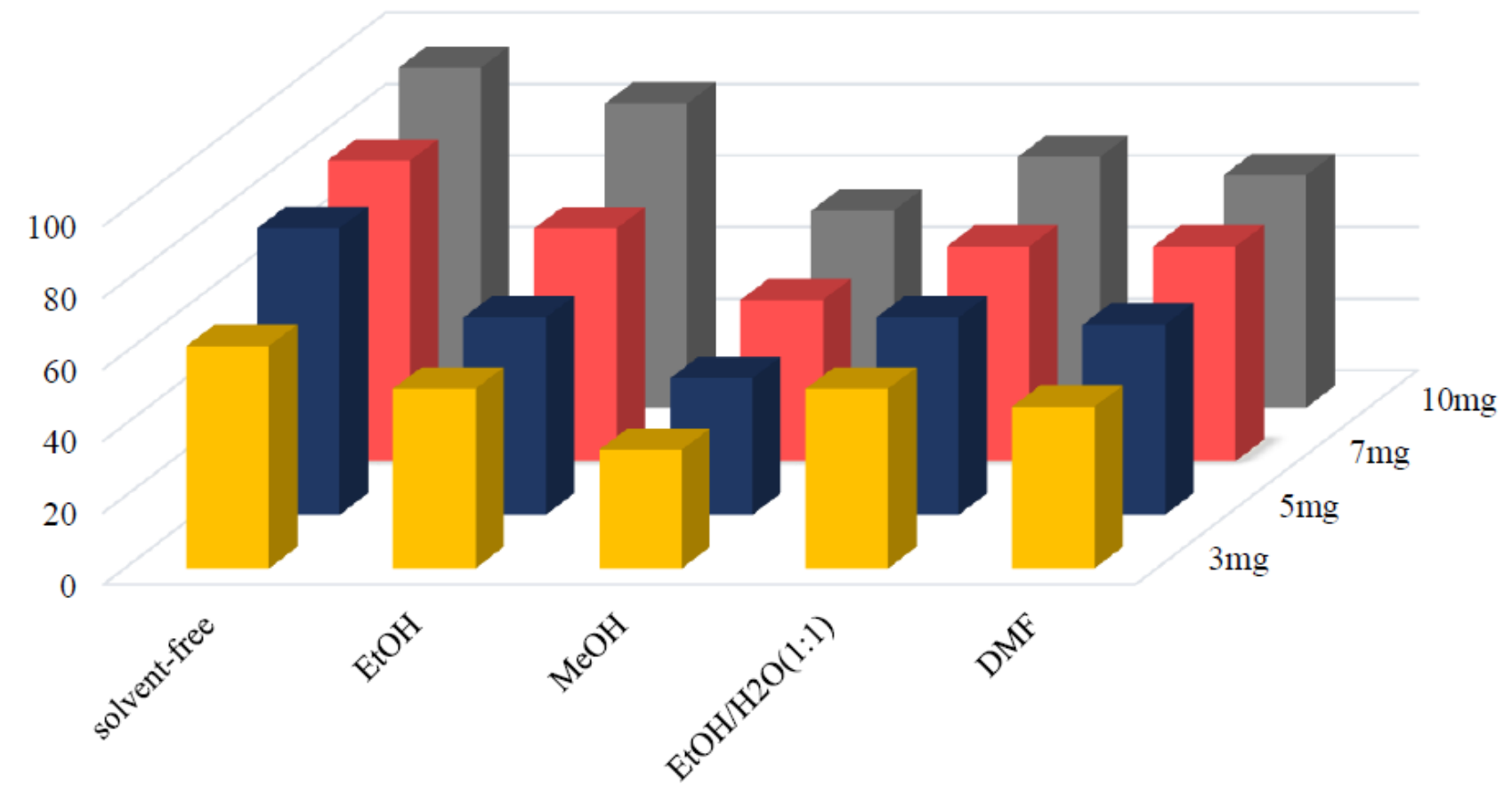

Figure 9

Effect of solvent and the amount of Fe304@Si02-APTS-EDTA-asparagine nanocatalyst (1) on the model reaction. 


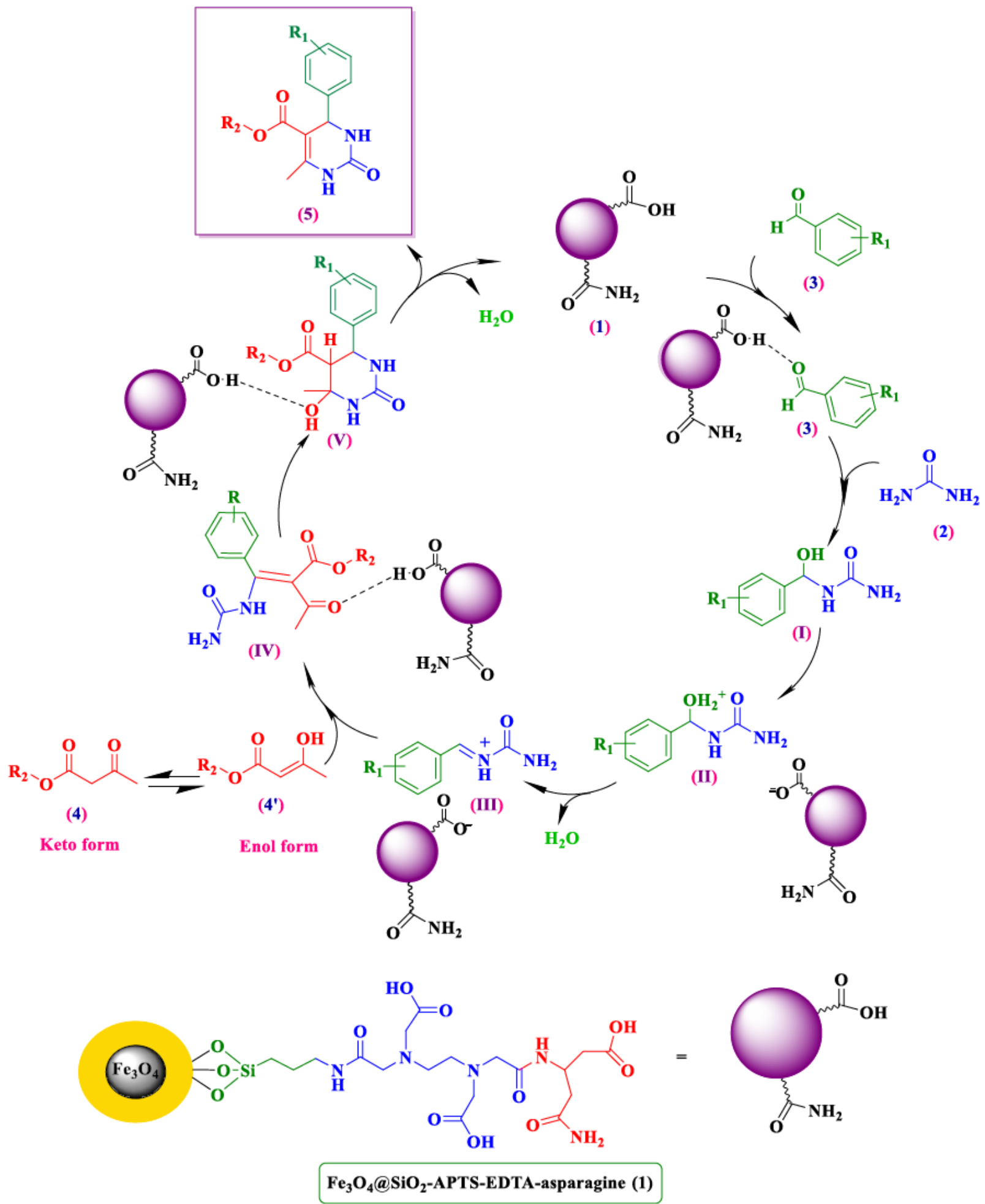

Figure 10

The proposed mechanism for the synthesis of 3,4-dihydropyrimidin-2(1H)-one derivatives using ethyl acetoacetate or methyl acetoacetate in the presence of Fe304@Si02-APTS-EDTA-asparagine nanocatalyst (1). 


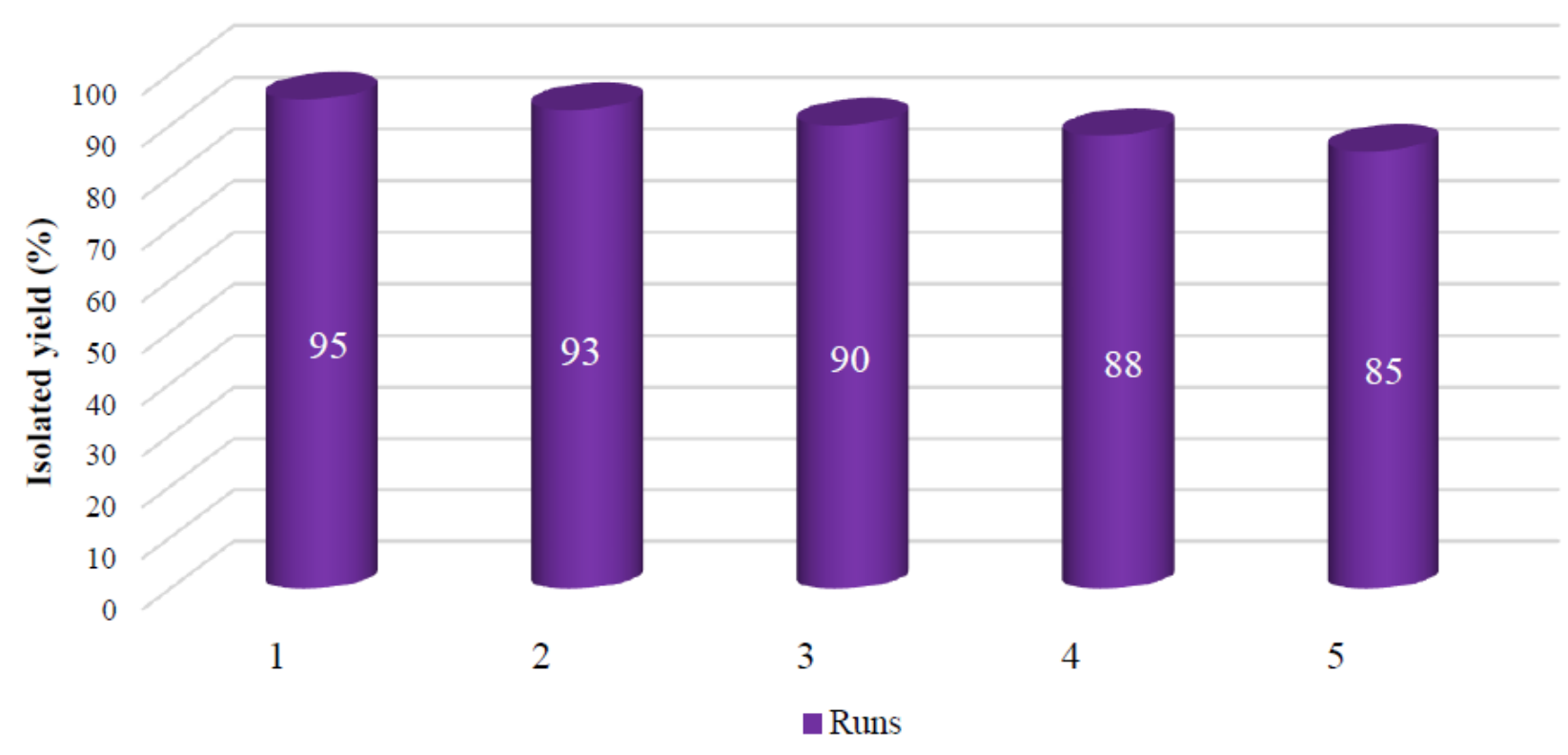

Figure 11

Reusability of the Fe304@Si02-APTS-EDTA-asparagine nanocatalyst (1) for the synthesis of 5a.

\section{Supplementary Files}

This is a list of supplementary files associated with this preprint. Click to download.

- Table23292022.pdf

- ElectronicSupportingInformationForReview3292022.pdf 